\title{
Bordering on Asian Paintings: Dye Analysis of Textile Borders and Mount Elements to Complement Research on Asian Pictorial Art
}

\author{
Diego Tamburini ${ }^{1, *(D)}$, Joanne Dyer ${ }^{1}$ (D) Teresa Heady ${ }^{2}$, Alice Derham ${ }^{3}$, Meejung Kim-Marandet ${ }^{3}$, \\ Monique Pullan ${ }^{2}$, Yu-Ping Luk ${ }^{4}$ and Imma Ramos ${ }^{4}$
}

1 Department of Scientific Research, The British Museum, Great Russell Street, London WC1B 3DG, UK; JDyer@britishmuseum.org

2 Department of Collection Care, Organic Materials Conservation, The British Museum, Great Russell Street, London WC1B 3DG, UK; theady99@yahoo.com (T.H.); MPullan@britishmuseum.org (M.P.)

3 Department of Collection Care, Pictorial Art Conservation, The British Museum, Great Russell Street, London WC1B 3DG, UK; ADerham@britishmuseum.org (A.D.);

MKim-Marandet@britishmuseum.org (M.K.-M.)

4 Department of Asia, The British Museum, Great Russell Street, London WC1B 3DG, UK; YLuk@britishmuseum.org (Y.-P.L.); IRamos@britishmuseum.org (I.R.)

* Correspondence: DTamburini@britishmuseum.org

check for updates

Citation: Tamburini, D.; Dyer, J.; Heady, T.; Derham, A.; Kim-

Marandet, M.; Pullan, M.; Luk, Y.-P.; Ramos, I. Bordering on Asian Paintings: Dye Analysis of Textile Borders and Mount Elements to Complement Research on Asian Pictorial Art. Heritage 2021, 4 , 4344-4365. https://doi.org/ 10.3390/heritage4040240

Academic Editor: Lucia Burgio

Received: 27 October 2021

Accepted: 11 November 2021

Published: 13 November 2021

Publisher's Note: MDPI stays neutral with regard to jurisdictional claims in published maps and institutional affiliations.

Copyright: () 2021 by the authors. Licensee MDPI, Basel, Switzerland. This article is an open access article distributed under the terms and conditions of the Creative Commons Attribution (CC BY-NCSA) license (https://creativecommons.org/licenses/by/4.0/).

\begin{abstract}
Mount components and textile borders represent important elements of Asian paintings. However, they are often side-lined or not considered an integral part of the original piece, as they may be later additions or may have been replaced during historic conservation or mounting interventions. Nevertheless, evidence is sometimes present that textile borders are contemporaneous to the production of the paintings they frame or, in the case of paintings found in archaeological contexts, to the time of deposition. Even when not contemporaneous with the paintings, the mount textiles are often of significant historic interest in themselves, showing a range of complex textile techniques and materials, and highlighting the re-use of fabrics. In all these cases, the study and reconstruction of the original colours of the borders enable further understanding of the holistic visual impact originally intended for the composition, as well as of the role of colour itself, which was used to emphasise, complement or contrast important pictorial themes or motifs in the paintings. Furthermore, the identification of dyes and dyeing techniques has the potential to support the production date and provenance of the paintings. In this study, the textile borders and some additional mounting elements of six paintings (late 9th-10th century CE) from the Library Cave, Mogao Grottoes, Dunhuang, China, one rare Korean portrait painting dated 1789 CE, and two Tibetan thangkas (18th century) were investigated with the aim to identify the dyes present. Fibre optic reflectance spectroscopy (FORS) was used to obtain information non-invasively and, when sampling was possible, high-performance liquid chromatography-tandem mass spectrometry (HPLCMS/MS) was used to obtain molecular identification of the dyestuffs employed in their production. Typical Asian dyes, such as gromwell (Lithospermum erythrorhizon), sappanwood (Biancaea sappan), safflower (Carthamus tinctorius), turmeric (Curcuma longa) and pagoda tree flower buds (Sophora japonica), were identified. Some of the dyeing techniques were commensurate with the geographical and temporal provenance assigned to these pieces. Considerations about fading and discolouration of the dyes enabled valuable additional information to be obtained that complements the evidence gleaned from the study of the paintings and informs conservators and curators on best practices in the preservation and display of these precious and delicate artworks.
\end{abstract}

Keywords: Asian art; textile mounting; Dunhuang; thangkas; natural dyes; reflectance spectroscopy; liquid chromatography; mass spectrometry 


\section{Introduction}

The concept of bordering and framing pictorial art has been adopted for thousands of years [1]. The origin and development of mounting East Asian paintings are thought to be closely related to the spread of Buddhism, although early forms of mounting practices existed in China prior to the introduction of Buddhism, as seen in the ancient silk paintings excavated from the Han Dynasty (206 BCE-220 CE) Mawangdui tombs [1-3]. The textile borders of banners and hanging paintings from the Mogao Caves, Dunhuang, largely dated to the 8 th to late 10th centuries, may be related to the development of the hanging scroll format in East Asian painting. There are variations in how hanging scrolls are mounted in different cultures across East Asia, but also many shared similarities [1,2,4]. Mounting can be generalised as a series of operations involving the application of several elements and materials to the back and sides of a painting, with the final outcome of framing it, strengthening it, and protecting it, thus allowing for easier transportation, storage and display [5]. The mounting elements also serve an aesthetic function, which contributes to embellishing the artwork [6]. They can function as additional spaces that carry symbols and added information that expands upon the meaning of the image they surround, which is particularly the case with Tibetan thangka paintings [4].

Borders are one of the elements of the mount. They are connected to the perimeter of the painting and can be constituted by textile or paper [1]. These materials share similar flexibility with the painting substrate-also usually textile or paper-and play an important role when the paintings are rolled for ease of storage and transportation [7]. This was a common practice, as scroll paintings are usually not intended to be on display for a long time, but rather to be shown for a short time on specific occasions [8]. In the case of thangkas, itinerant monks bring the paintings with them when they move from monastery to monastery [4].

As textile and paper are quite delicate materials, which can easily degrade, borders and mountings were, and often still are, seen as "sacrificial" elements, which could, if necessary, be discarded and replaced [9]. This is one of the reasons why they are often considered a peripheral topic in art history. However, their study can help to elucidate valuable information about the development of mounting practices, the use of materials, the overall artistic intention, and the spiritual/religious significance behind the paintings. For conservators, the relative light sensitivities of the different dyes used to colour the textiles is also a major issue in determining suitability for, and length of, any display. Additionally, evidence is sometimes present that textile borders are contemporaneous to the production of the paintings they frame or, in the case of paintings found in archaeological contexts, to the time of deposition. However, fading and discolouration commonly occur and, in some cases, to such an extent that the original colour almost disappears or is completely changed. Therefore, the reconstruction of the original colour of the textile borders is also a crucial element to fully understand the artwork as originally intended.

Different circumstances-as explained in the Materials and Methods section-led to a scientific investigation being carried out at the British Museum with the aim to gather information from the textile borders of several Asian paintings, in order to support their study, conservation and display. The artworks included six paintings (late 9th-10th century CE) from the Library Cave, Mogao Grottoes, Dunhuang, China, one rare Korean portrait painting dated $1789 \mathrm{CE}$, and two Tibetan thangkas (18th century), thus spanning different time periods, geographical areas and mounting techniques. The research focused on dye analysis, which is a challenging task from a scientific point of view. In fact, the identification is generally based on the availability of an appropriate database of reference materials and reference data, which can change drastically depending primarily on the geographical origin of the textiles under investigation, as dyers have generally drawn from the natural world in surrounding areas [10]. The British Museum has undertaken research on Asian dyes for several years, with the result of building an in-house database to be exploited for Asian dye identification [11-13]. This research, combined with information from various 
other sources [14-27], provides a good foundation from which to undertake further studies into Asian dyes.

In terms of analytical techniques, recent research has shown that substantial information about the nature of Asian dyes can be obtained non-invasively, by using a combination of broadband multispectral imaging (MSI) and fibre optic reflectance spectroscopy (FORS) [11]. Other non-destructive surface techniques, such as time of flight secondary ion mass spectrometry (TOF-SIMS) [28] and fluorescence spectroscopy [29,30], have been applied to the identification of a limited number of Asian colourants. Surface-enhanced Raman spectroscopy (SERS) is also a valid approach for the identification of dyes, although a small sample (ca. $80 \mu \mathrm{g}$ ) is required [31-33]. However, all these techniques share the limitation of not reaching an advanced level of molecular detail. In fact, dyes are generally mixtures of molecules, and some of them do not produce signals specific enough to enable their identification non-invasively, especially most yellow dyes [34,35]. Mixtures of dyes can also be difficult to identify non-invasively $[23,36]$. By contrast, when sampling is possible, highly detailed information relating to the molecular structure of the dye molecules can be obtained by using high-performance liquid chromatography (HPLC) [37]. The technique enables all the molecular components present in the sample to be chromatographically separated and identified singularly so that the exact plant or animal source(s) of the dye(s) are identified at the species level [38-42]. The identification is achieved by recording the UV/Vis absorption spectra of the dye molecules with a photo-diode array (PDA) detector [43-45], their fluorescence spectra with fluorescence (FL) detector [46], and/or their masses with a mass spectrometer (MS) [12,18-20,22,23,47,48]. The advantages of using MS are related to the possible identification of degradation products and relevant non-coloured molecules [15,49]. High-resolution mass spectrometry (HRMS) and tandem mass spectrometry (MS/MS) offer the additional advantages of elucidating unknown structures, distinguishing between isomers and potentially identifying new sources of dyes $[12,13,25-27,42,50-54]$.

Recent studies have shown the advantages of using a combined investigative approach to dye analysis, starting with non-invasive techniques and using the results obtained noninvasively to guide a selective sampling campaign that minimises the number and size of samples $[23,55,56]$. Although this approach represents an ideal scenario, the reality of investigations carried out on museum collections often dictates that compromises are made, mostly due to time constraints and the inability to sample certain objects due to their state of conservation or ethical considerations. This was the case in these investigations and, as a result, some of the analyses were only carried out non-invasively, and others only invasively. The range of information that is obtained from both approaches is therefore showcased through the case studies presented, highlighting that, even though ideal protocols could not be followed, valuable information was obtained whilst making sound and ethically driven compromises.

\section{Materials and Methods}

\subsection{Paintings from Cave 17 (Library Cave), Mogao Grottoes, Dunhuang, China}

Cave 17, known as the Library Cave, is one of the most famous parts of the Mogao Grottoes, a cave temple site near the oasis town of Dunhuang, on the edge of the Gobi Desert in western China. The cave had been sealed in the early 11th century and, when discovered in 1900, was found to contain thousands of scrolls, manuscripts, paintings and textiles [57].

The British Museum's collection from Cave 17 includes over 300 paintings, both intact pieces and fragments, which were acquired by Sir Marc Aurel Stein in 1907. Some paintings have textile borders that have partially or fully survived at least from the time that they were sealed in the cave. The textile borders appear in a variety of colours and patterns, from plain beige, blue, red, brown or dark purple colours to patchwork strips of different colours, as well as printed damask silk with floral motifs using the clamp dye resist technique. Both silk and cellulosic fabric (hemp or linen) borders are present. The material from the 
Library Cave survived in remarkably good condition thanks to the fact that the chamber was sealed, thus preventing the objects from being exposed to light and limiting drastically the fluctuations in humidity, temperature and oxygen flow. Nevertheless, the colours on the paintings and textiles have inevitably changed or faded both during the deposition in the archaeological environment and during the one hundred years after their removal from the cave. Some of the textiles may have also faded and discoloured through use prior to deposition. The main questions related to the textile borders are therefore what dyes were used and what the original colours would have looked like. Six paintings are discussed in this study. However, the study was part of a broader investigation that started as a request for analysis from curator Yu-Ping Luk with the aim to clarify the role of the textile borders and their colours in a higher number of Dunhuang paintings in the BM collection [58].

\subsubsection{Accession Number 1919,0101,0.16 (DP16)}

The painting is on silk and represents Śākyamuni seated on a lotus throne, under a canopy surrounded by Bodhisattvas Ākāśagarbha and Ratnaguna, and disciples (Figure 1, left). Donor figures are present in the bottom register. The production date is $953 \mathrm{CE}$, as per the inscription [59]. The textile border is plain silk, and the colour appears brown or a discoloured dark purple. Analyses were carried out to clarify the actual original colour. The painting is referred to in the text as DP16 (Dunhuang Painting 16). v
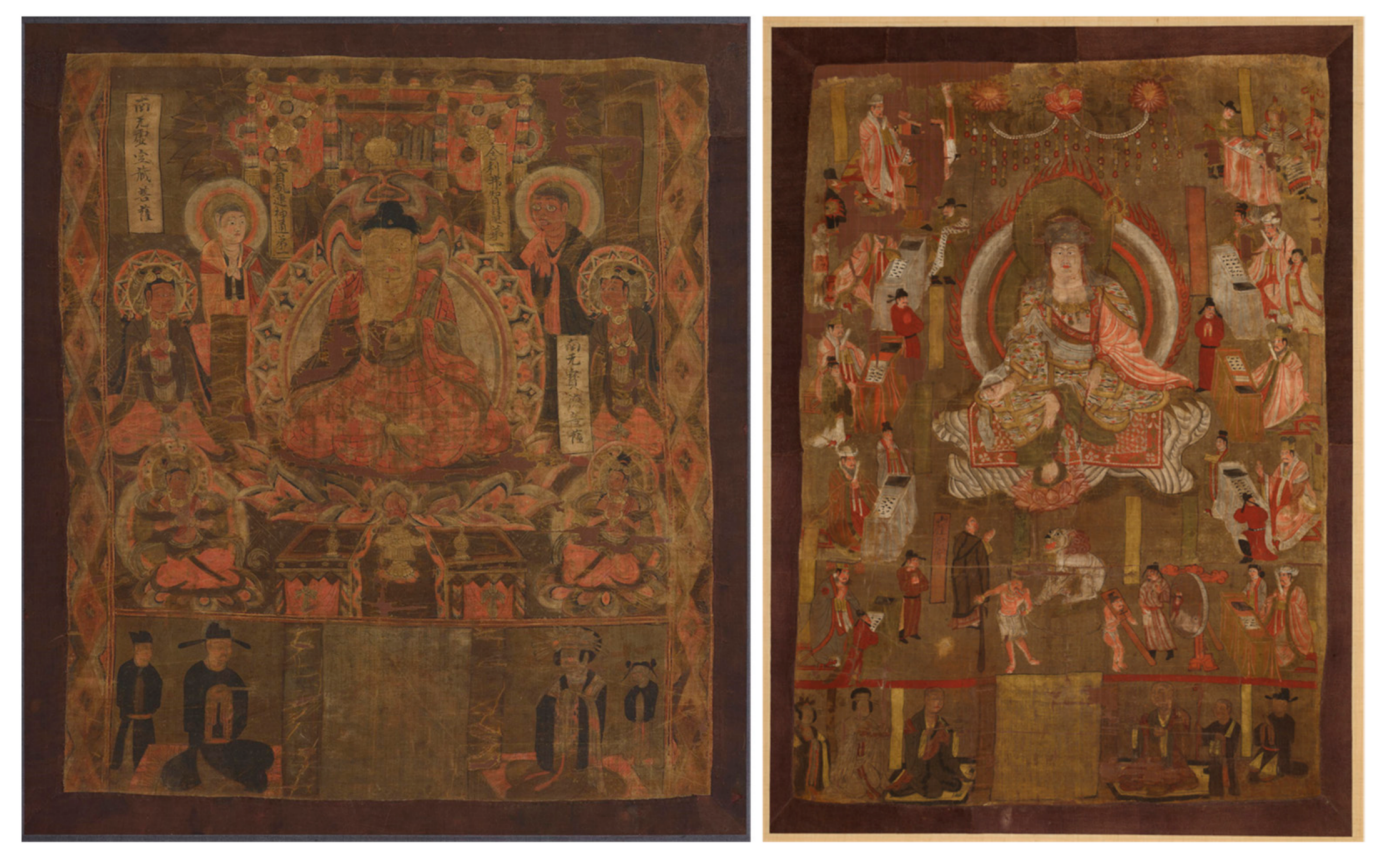

Figure 1. Images of Dunhuang painting 1919,0101,0.16 (DP16) on the (left) (height: $76.6 \mathrm{~cm}$; width: $68.4 \mathrm{~cm}$; date $953 \mathrm{CE}$ ), and Dunhuang painting 1919,0101,0.23 (DP23) on the (right) (height: $91 \mathrm{~cm}$; width: $65.5 \mathrm{~cm}$; date 926-975 CE). (C) The Trustees of The British Museum.

\subsubsection{Accession Number 1919,0101,0.23 (DP23)}

The painting is on silk and represents Kșitigarbha in the centre, seated on a rock under a canopy, holding a staff and a cintamani (flaming jewel) (Figure 1, right). At the two sides are the Ten Kings of Hell, each one seated behind a desk like a magistrate, flanked by assistants. Before the Bodhisattva stands the monk Daoming with his lion, and an ox-headed jailor leading the soul of a man wearing a cangue, who is viewing his sins in a mirror. Blank cartouches stand on alternate sides of the Ten Kings. Two inscribed cartouches stand at the side of the figure of Daoming. In the bottom section, donor figures kneel at the sides of a central blank panel. The production date is ca. 926-975 CE [60]. The textile border is made of cellulosic fabric (probably hemp or linen) and the colour appears 
brown or a discoloured dark purple. Analyses were carried out to clarify the actual original colour. The painting is referred to in the text as DP23 (Dunhuang Painting 23).

\subsubsection{Accession Number 1919,0101,0.30 (DP30)}

The painting is on silk and represents a seated Buddha with hands in the vitarkamudra (gesture of reasoning or discussion), and therefore possibly Maitreya or Amitābha. The whole figure, with nimbus and aureole, is set within a large white circle (Figure 2, left). Two donor figures are depicted on either side of a central blank cartouche. The production date is 10th century [61]. The textile border is a coarse silk twill (2:1) and the colour is bright red. The painting is referred to in the text as DP30 (Dunhuang Painting 30).
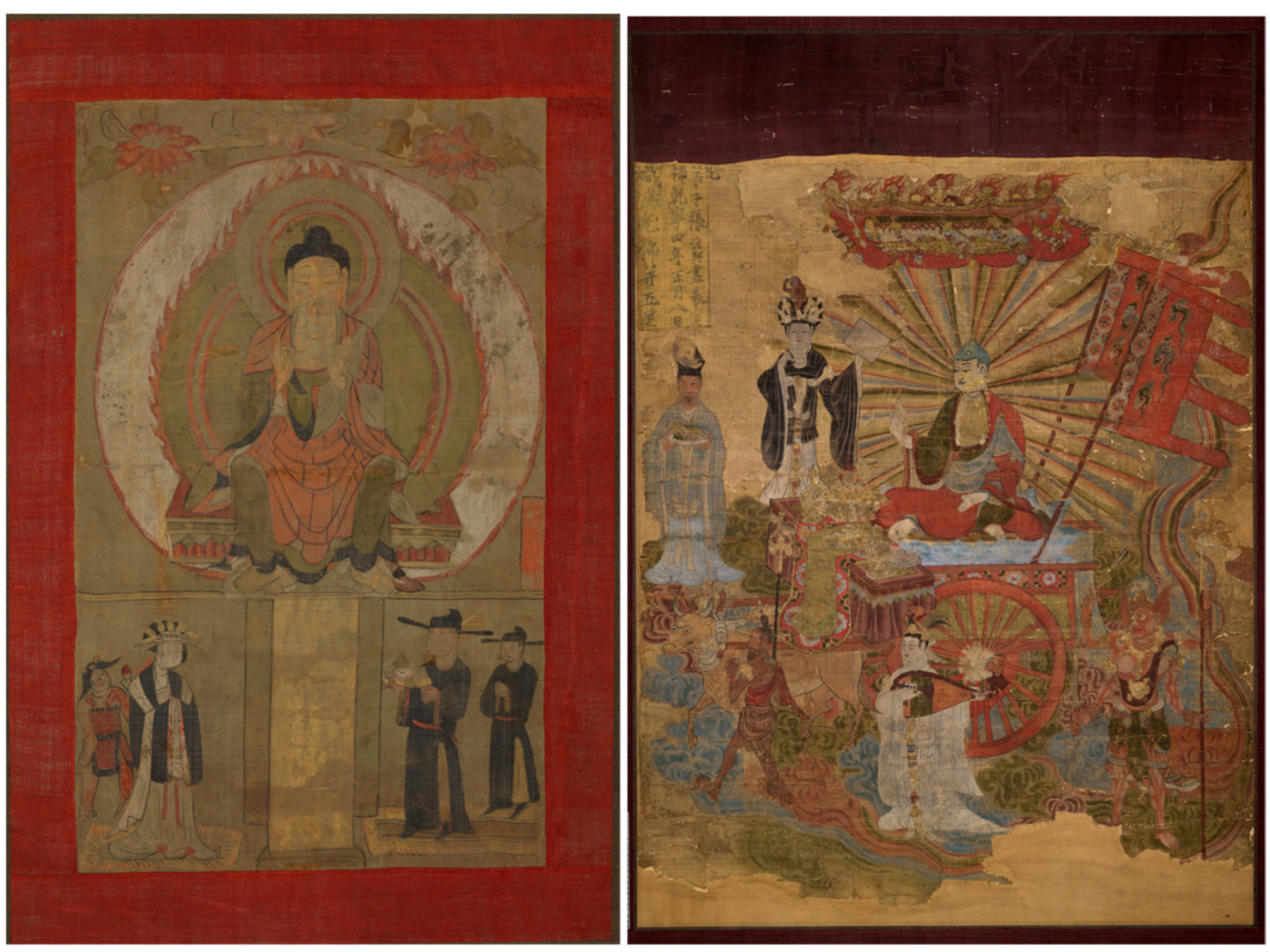

Figure 2. Images of Dunhuang painting 1919,0101,0.30 (DP30) on the (left) (height: $64.6 \mathrm{~cm}$; width: $39.4 \mathrm{~cm}$; date 10th century), and Dunhuang painting 1919,0101,0.31 (DP31) on the (right) (height: $80.4 \mathrm{~cm}$; width: $55.4 \mathrm{~cm}$; date $897 \mathrm{CE})$. (C) The Trustees of The British Museum.

\subsubsection{Accession Number 1919,0101,0.31 (DP31)}

The painting is on silk and represents the Tejaprabha Buddha (Buddha of the Blazing Lights), shown seated on a chariot with the Five Planets represented by female and male figures with their respective attributes (from left clockwise): Jupiter as an official, Mercury as a lady holding a brush, Mars as a four-armed warrior demon, Venus playing the pipa and Saturn as an aged Indian attending to the bull pulling the cart (Figure 2, right). The production date is $897 \mathrm{CE}$, as per the inscription [62]. A band of dark purple silk remains at the top, but the bottom part is lost together with the lower part of the painting. The painting is referred to in the text as DP31 (Dunhuang Painting 31).

\subsubsection{Accession Number $1919,0101,0.54$ (DP54)}

The painting is on silk and represents Avalokiteśvara seated on a lotus seat with the Good and Bad Boys (Figure 3, left). In the lower register are two rows of male, female and child donors, with central inscription and identifying cartouches. The production date is $983 \mathrm{CE}$, as per the inscription [63]. The textile border is made of strips of thin silk with blue, pink, brown and crimson colours, symmetrically arranged. Five suspension loops are also 
present. The ones in the corners are beige (probably undyed), two are blue, and the middle one is purple. The painting is referred to in the text as DP54 (Dunhuang Painting 54).
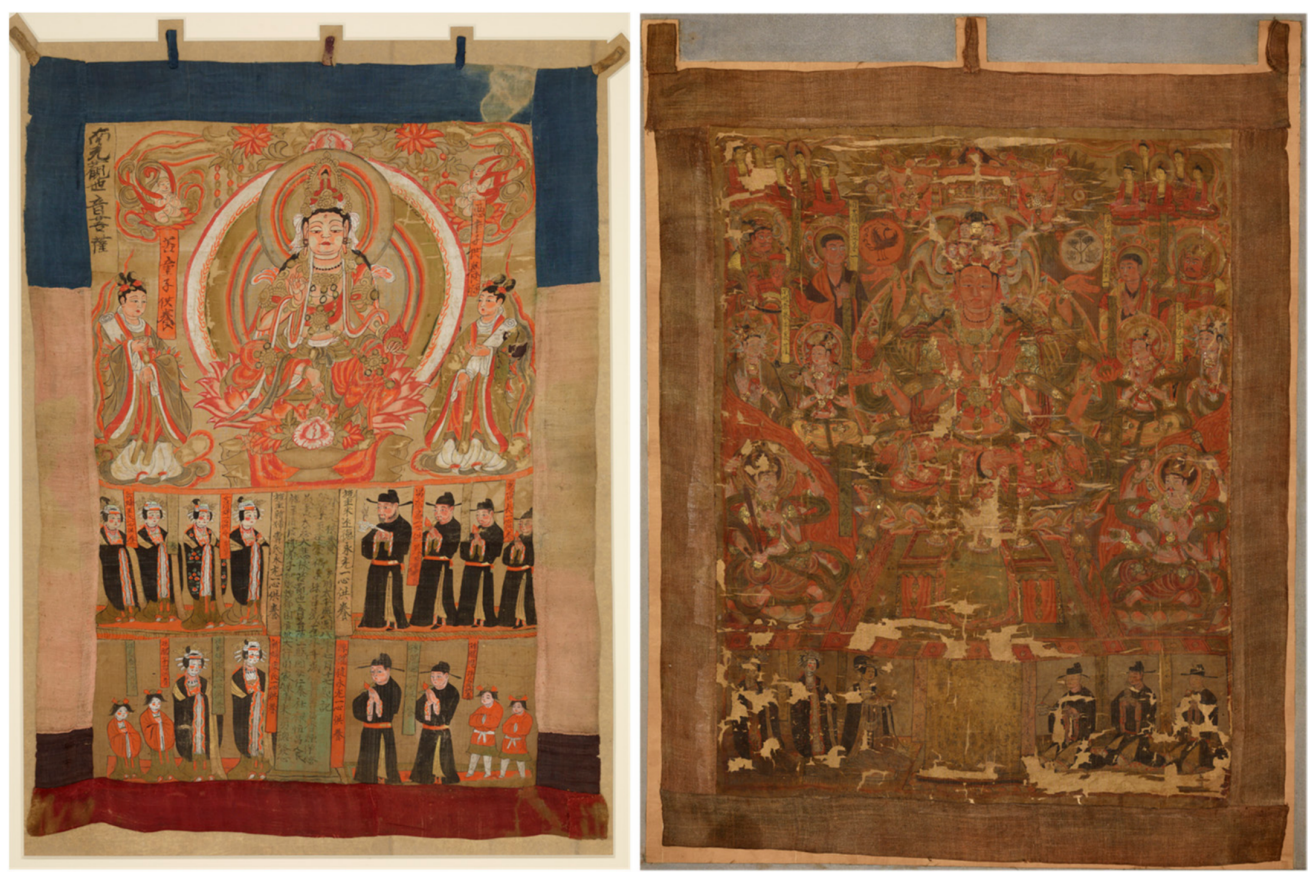

Figure 3. Images of Dunhuang painting 1919,0101,0.54 (DP54) on the (left) (height: $99 \mathrm{~cm}$; width: $59.5 \mathrm{~cm}$; date $983 \mathrm{CE}$ ), and Dunhuang painting 1919,0101,0.63 (DP63) on the (right) (height: $97 \mathrm{~cm}$; width: $74.3 \mathrm{~cm}$; date 970-980). (C) The Trustees of The British Museum.

\subsubsection{Accession Number $1919,0101,0.63$ (DP63)}

The painting is on silk and represents Avalokiteśvara seated on a lotus throne, shown with eleven heads and six arms, the Buddhas of the Ten Directions, bodhisattvas, lokapalas (guardian kings) and two Vajrapāni (thunderbolt bearers), each one flanked by a cartouche with his name (Figure 3, right). Three male and three female donors are depicted in the lower section at both sides of a central inscription panel. The production date is ca. 970-980 [64]. The textile border and three suspension loops are made of coarse brownish cellulosic fabric, probably hemp or linen. However, the original colour may have been different, and analyses were carried out to clarify this point. The painting is referred to in the text as DP63 (Dunhuang Painting 63).

\subsection{Hanging Scroll from Korea-Accession Number 1996,0329,0.1 (K1)}

The painting is on silk and represents the portrait of Ch'ae Che-Gong (1720-1799 CE), Prime Minister of Korea under King Ch'ongjo (reign 1776-1800 CE) of the Joseon dynasty (Figure 4). The portrait was made in 1789 CE possibly by court artist Yi Myong-Gi (ca. 1760-1820 CE). It is a typical example from late 18th-century Korean portraiture. Seen in a three-quarter view, the crossed-legged sitter sits on a cushion made of tiger skin, wearing a pink robe and a rhinoceros horn belt and a traditional Korean hat [65].

It is one of the few examples of painted portraits that survive in original Korean mounts. The textile mounting is in silk. The front shows a very light aqua colour and the back is a darker shade of blue. Several decorative elements are included, such as red knotted tassels (yuso), roller knob, hanging rod, and metal washer [6]. Given the scarcity of Korean portraits kept in their original mount, the investigation of the colours used in the mounting elements represents a point of reference to better understand Korean traditional mounting techniques. The painting is referred to in the text as K1 (Korean 1). 

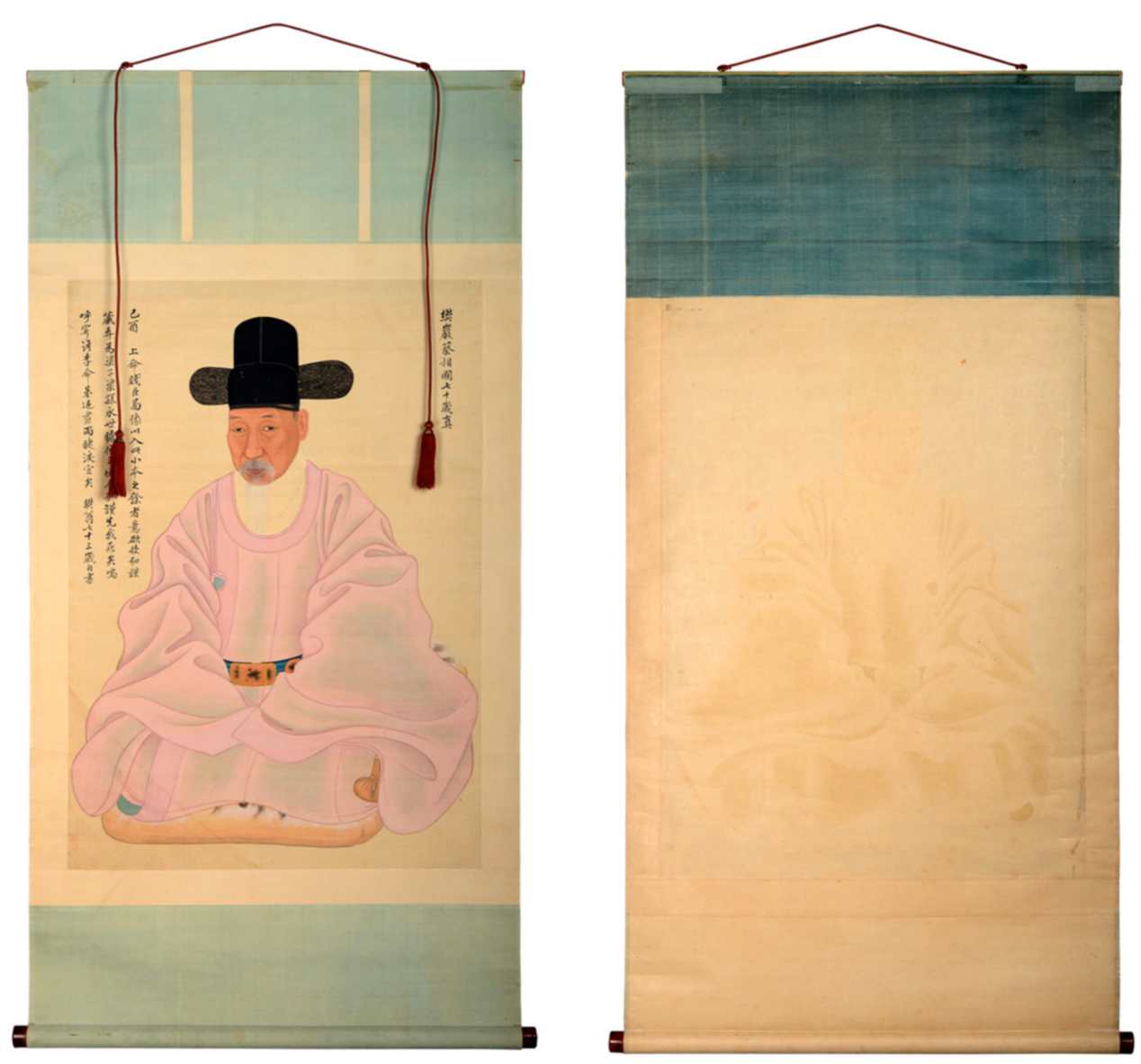

Figure 4. Image of the recto and verso of Korean hanging scroll 1996, 0329, 0.1 (K1), showing the portrait of Ch'ae Che-Gong (1720-1799 CE). Dimensions are $142.0 \times 75.5 \mathrm{~cm}$ with mount and $96.5 \times 59.5 \mathrm{~cm}$ without. Date is 1789 CE. (C) The Trustees of The British Museum.

\subsection{Tibetan Thangkas}

Thangkas are complex multi-material sacred objects. They are meant to be portable and generally consist of a central painted image surrounded by highly decorative silk brocade borders. Wooden rods are attached to the top and bottom to allow for hanging and a veil is present to protect the image [9].

Analyses were carried out on two thangkas (accession number 1956,0714,0.40 and $1956,0714,0.41$ ) in the framework of a conservation campaign that took place in 2019, in order to safely display them in the BM exhibition "Tantra: enlightenment to revolution" (24 September 2020-24 January 2021). The scientific investigation involved not only the textile borders but also the painting materials [66]. The main question about the dyes was whether they were natural or synthetic, as this could influence their stability and sensitivity to light. These doubts also related to the question as to whether the textiles borders were later additions, as the thangkas production date is given as 18th century. Additionally, the original colour of the dyed textile was of interest to reconstruct the appearance of the thangkas.

In both thangkas, the bottom part of the silk border tapers outwards, as indicative of an Eastern Tibetan type of mount [4]. The silk veil is dyed yellow, with a tie-dyed pattern of red and green flowers, which is common for both Central and Eastern Tibetan style mounts [7]. The thangkas have a thang sgo (distinctive cloth patch, or "door") on the lower part of the mount, which is always found on Central Tibetan-style mounts [7]. Initial examination of the silk textile borders revealed that these were probably made from several re-used garments, including a Chinese robe of high quality. In fact, the brocades were sometimes made from important clothing belonging to specific monks, to further enhance 
the sacredness of the objects [67]. One set of stitch holes joining the borders to the paintings was observed, which may suggest that these are the first and only borders to be attached to the paintings. However, re-mounting is common for thangkas, and the possibility of the same stitch holes being re-used to mount new textile borders cannot be completely excluded.

\subsubsection{Accession Number 1956,0714,0.40 (T1)}

The painting is on a cellulose-based textile, likely cotton, and represents the Mahasiddha Saraha in the centre surrounded by five other Mahasiddhas (Nagarjuna, Virupa, Dombi Heruka, Padmavajra and Saroruhavajra), along with Butön Rinchendrup (1290-1364), the 11th Abbot of Shalu Monastery and a Sakya master (Figure 5, left). Some Mahasiddhas were real historical figures while others were legendary. They were instrumental in the transmission of Tantric Buddhist teachings from India to the Himalayas from around the 8th century, and their lives were later celebrated in literary hagiographies [68]. The production date is the 18 th century.
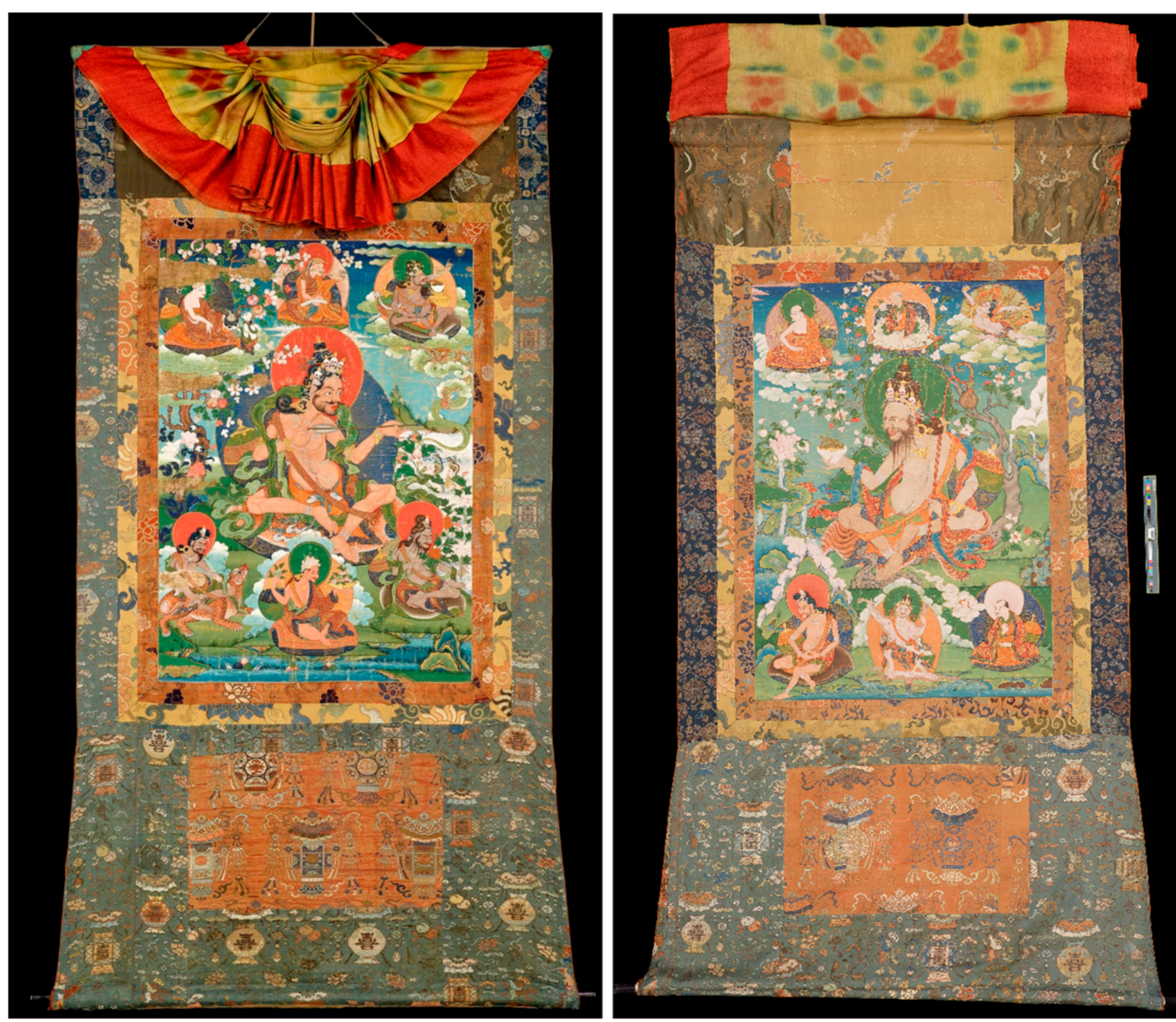

Figure 5. Images of Tibetan thangka 1956,0714,0.40 (T1) showing Mahasiddha Saraha (height: $83 \mathrm{~cm}$; width: $59 \mathrm{~cm}$; height (with mount): $185 \mathrm{~cm}$; width (with mount): $107.5 \mathrm{~cm}$; 18th century), and Tibetan thangka 1956,0714,0.41 (T2) showing Mahasiddha Ananta (height: $82.2 \mathrm{~cm}$; width: $58.5 \mathrm{~cm}$; height (with mount): $179 \mathrm{~cm}$; width (with mount): $111 \mathrm{~cm}$; 18th century). (C) The Trustees of The British Museum.

During conservation treatment, the underside of the brocades was revealed and showed the significant extent of fading which had occurred (see Figure 10 for an example). It was also observed that the border comprises six separate textiles. The main border is a blue Chinese brocade made up of eight fragments. The thang sgo window at the centre bottom part of the border is made up of an orange Chinese brocade, which is different from the orange textile used in the inner border. The inner borders are made up of four pieces of 
two separate brocades, one yellow and one orange. Above the yellow inner border, a blue brocade continues the borders on both sides. Finally, a satin discontinuous brocade made up of three pieces makes up the centre of the top border. This textile shows evidence of an unpicked seam as if it was from a garment. It is of very high quality and has butterflies, dragons and auspicious symbols placed randomly.

Four samples of non-faded threads $(\mathrm{ca} .0 .5 \mathrm{~cm})$ were taken from the back of the textile borders for HPLC-MS/MS analysis. The samples included red from the inner border (orange on the front), pink from flower details (almost completely faded on the front), green from details on the yellow inner border, and blue from the main border.

The painting is referred to in the text as T1 (Thangka 1).

\subsubsection{Accession Number 1956,0714.0.41 (T2)}

The painting is on a cellulosic textile and represents the Mahasiddha Ananta in the centre surrounded by five other Mahasiddhas (Aryadeva, Nalendrapa, Karupaka, Dasiripa and Dringi Shukchen), along with Sachen Künga Nyingpo (1092-1158), the first of the five venerable Sakya masters of Tibet (Figure 5, right). The production date is the 18th century.

Similarly to T1, the underside of the brocade was revealed during conservation treatment The border is made up of four of the same silk brocades as T1, which include the main blue border (seven fragments), the central thang sgo window (four fragments), the yellow inner border (four fragments), and one of the two satin brocades in the top border (four fragments). The other silk satin in the top border is different and has a continuous brocade of gilded paper strips making up most of the design. The inner orange border is different from the one in $\mathrm{T} 1$. The two outer borders are also made up of a different blue brocade.

Five samples of non-faded threads $(\mathrm{ca} .0 .5 \mathrm{~cm})$ were taken from the back of the textiles for HPLC-MS/MS analysis. The samples included red/orange from the thang sgo window, pink from details (almost completely faded on the front), yellow from the inner border, dark yellow from a detail, and blue from a detail, thus complementing the colour palette of the textile borders in both $\mathrm{T} 1$ and $\mathrm{T} 2$.

The painting is referred to in the text as T2 (Thangka 2).

\subsection{FORS}

Reflectance spectra were recorded from several areas of the textile borders of the Dunhuang paintings and the Korean painting. An Avantes (Apeldoorn, The Netherlands) AvaSpec-ULS2048XL-USB2 spectrophotometer equipped with an AvaLight-HAL-S-IND tungsten halogen light source was used. The detector and light source were connected with a fibre optic bundle to an FCR-7UV200-2-1.5 $\times 100$ probe. In this configuration, light was sent and retrieved by the bundle set at approximately $45^{\circ}$ from the surface normal, thus excluding specular reflectance. The spectral range of the detector was 200-1160 nm; nevertheless, due to poor blank correction on both the extremes of the range, only the range between 400 and $900 \mathrm{~nm}$ was considered. As per the features of the monochromator (slit width $50 \mu \mathrm{m}$, grating of UA type with 300 lines $/ \mathrm{mm}$ ) and of the detector (2048 pixels), the best spectra resolution was $2.4 \mathrm{~nm}$ calculated as the full width at half maximum (FWHM). Spectra were referenced against the WS-2 reference tile provided by Avantes. The diameter of the investigated area on the sample was approximately $1 \mathrm{~mm}$, obtained by setting the distance between probe and sample at $1 \mathrm{~mm}$. The instrumental parameters were as follows: $50 \mathrm{~ms}$ integration time, 20 scans for a total acquisition time of $1 \mathrm{~s}$ for each spectrum. The whole system was managed by the software AvaSoft 8 for Windows ${ }^{\mathrm{TM}}$ (AvaSoft, Navalur, India). The reflectance (R) spectra were also converted into apparent absorption spectra by calculating $\log (1 / \mathrm{R})$. 


\subsection{HPLC-ESI-MS/MS}

Nine samples from the two Tibetan thangkas were treated using the method published in [13], which briefly consists of a double mild extraction procedure using DMSO and a mixture of methanol/acetone/water/0.5M oxalic acid 30:30:40:1 $(v / v / v / v)$. The method has proven suitable for the analysis of organic colourants in both dyes $[12,15,55,56,69-71]$ and pigments formulations [36,72-74].

Analyses were carried out using a 1260 Infinity HPLC (Agilent Technologies), coupled to a Quadrupole-Time of Flight tandem mass spectrometer 6530 Infinity Q-ToF detector (Agilent Technologies) by a Jet Stream ESI interface (Agilent Technologies). Separation was achieved using a Zorbax Extend-C18 column $(2.1 \mathrm{~mm} \times 50 \mathrm{~mm}, 1.8 \mu \mathrm{m}$ particle size $)$ with a $0.4 \mathrm{~mL} / \mathrm{min}$ flow rate and $40{ }^{\circ} \mathrm{C}$ column temperature, and a gradient of water with $0.1 \%$ formic acid (eluent $\mathrm{A}$ ) and acetonitrile with $0.1 \%$ formic acid (eluent $\mathrm{B}$ ). The elution gradient was programmed as follows: initial conditions $95 \%$ A, followed by a linear gradient to $100 \% \mathrm{~B}$ in $10 \mathrm{~min}$ and held for $2 \mathrm{~min}$. Re-equilibration time for each analysis was $10 \mathrm{~min}$. A $5 \mu \mathrm{L}$ injection volume was adopted for MS experiments and $10 \mu \mathrm{L}$ for MS/MS experiments.

The ESI operating conditions were: drying gas $\left(\mathrm{N}_{2}\right.$, purity $\left.>98 \%\right)$ temperature $350{ }^{\circ} \mathrm{C}$ and flow $10 \mathrm{~L} / \mathrm{min}$; capillary voltage $4.0 \mathrm{kV}$; nebulizer gas pressure $40 \mathrm{psig}$; sheath gas $\left(\mathrm{N}_{2}\right.$, purity $>98 \%$ ) temperature $375{ }^{\circ} \mathrm{C}$ and flow $11 \mathrm{~L} / \mathrm{min}$. High-resolution MS spectra were acquired in negative mode in the range 100-1700 m/z. The fragmentor was kept at $150 \mathrm{~V}$, nozzle voltage $1000 \mathrm{~V}$, skimmer $65 \mathrm{~V}$, octapole RF $750 \mathrm{~V}$.

MassHunter ${ }^{\circledR}$ Workstation Software (Agilent Technologies, Santa Clara, California, USA) was used to carry out mass spectrometer control, data acquisition, and data analysis. Identifications were obtained by comparing the results from the samples with an in-house database [12].

\section{Results}

\subsection{Dunhuang Paintings}

A non-invasive investigation was the only possible approach for the dye analysis of these precious textiles, as the paintings were lined on textile backings that prevented access to sampling areas. Thus, FORS was used, drawing from a reference database of Asian dyes previously built in the framework of a larger project [11].

The textile borders of DP16, DP23 and DP31 appear to be dark brown in colour, possibly with a purple hue. In Serindia, Aurel Stein describes this colour as a "faded purple" [75]. The FORS results show that DP23 and DP31 are dyed with gromwell (L. erythrorhizon), a plant of the Boraginaceae family from whose roots a purple dye is extracted. Gromwell is mentioned as a treasure good in some documents found in Dunhuang [10] and was abundantly found in other Dunhuang textiles [11,12,22]. It produces a distinctive spectrum with absorbance maxima at ca. 550 and $595 \mathrm{~nm}$ (in very good quality spectra, a third maximum is generally observed at $510 \mathrm{~nm}$ ) [11], as shown in Figure 6b. Artificial ageing of silk dyed with gromwell also revealed that the vibrant purple colour easily turns towards a brown shade upon discolouration [11], thus justifying the dark colour observed today on these textiles. By contrast, the FORS results obtained from DP16 suggest that this textile was intentionally dyed brown, possibly using tannins. In fact, poor spectral features and a broad absorption range in the visible part of the spectrum are characteristic of brown shades possibly obtained with iron-tannin complexes [76], as shown in Figure 6a.

The colourant for the red border of DP30 produced an apparent absorbance spectrum without specific spectral features, but with a relatively broad maximum absorbance centred at ca. $540 \mathrm{~nm}$ (Figure 6c), which matches with reference spectra obtained from sappanwood (B. sappan) [11,77]. Sappanwood was also abundantly found in other Dunhuang textiles and is known to be a traditional Asian dye [22]. However, it is also known to fade easily [11,50], hence the brightness of the red colour of this textile is a remarkable example of excellent colour preservation. 


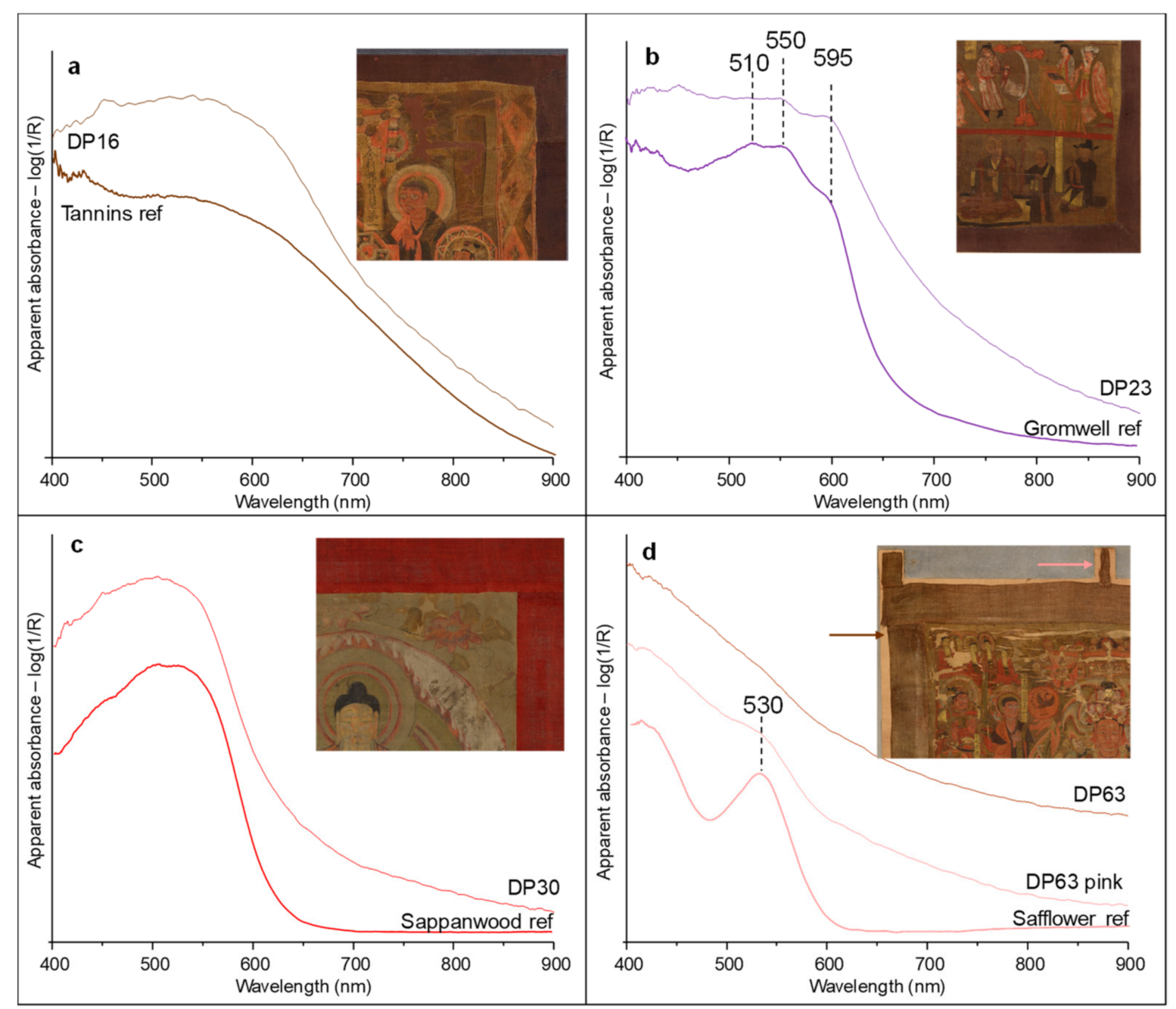

Figure 6. FORS spectra presented as apparent absorbance spectra of (a) DP16 and reference sample dyed with tannins, (b) DP23 and reference sample dyed with gromwell, (c) DP30 and reference sample dyed with sappanwood, and (d) DP63 (safflower from very light pink areas and non-conclusive spectrum from completely faded/discoloured areas) and reference sample dyed with safflower.

On the contrary, the textile border of DP63 appears faded and/or discoloured to a point where it is difficult to hypothesise whether the textile was originally dyed or the present colour is the result of soiling and natural darkening of the cellulosic fabric. On closer inspection, however, some areas with a very light pink colour were observed, including the middle suspension loop. The results from FORS obtained from these areas showed a weak absorption maximum at ca. $530 \mathrm{~nm}$, which suggests the presence of safflower (C. tinctorius) $[11,70]$, as shown in Figure 6d. Other areas of the textile produced inconclusive spectra, as also included in Figure 6d. Safflower dye is very light sensitive [11,78]. Thus, the results suggest that safflower was originally used to dye the entire border [11,78]. In the British Museum's collection, a banner from Dunhuang (accession number 1919,0101,0.156) also presents a cellulosic fabric dyed with safflower, but the colour is very well-preserved, thus giving an idea of how bright the pink colour would have been originally. 
The multi-coloured border of DP54 is also in a good state of preservation and the results obtained from FORS are a precise summary of the dyes already discussed for the other paintings. In fact, the bright red was obtained with sappanwood, the pink with safflower, the purple in the middle hanging loop with gromwell, and the brown with tannins (Figure 7). Additionally, the top part of the border is blue. The characteristic spectrum of indigo was obtained by FORS (Figure 7). As already underlined for DP63, safflower dye is very light-sensitive, thus the pink section of the border would originally have been a brighter red/salmon pink colour.
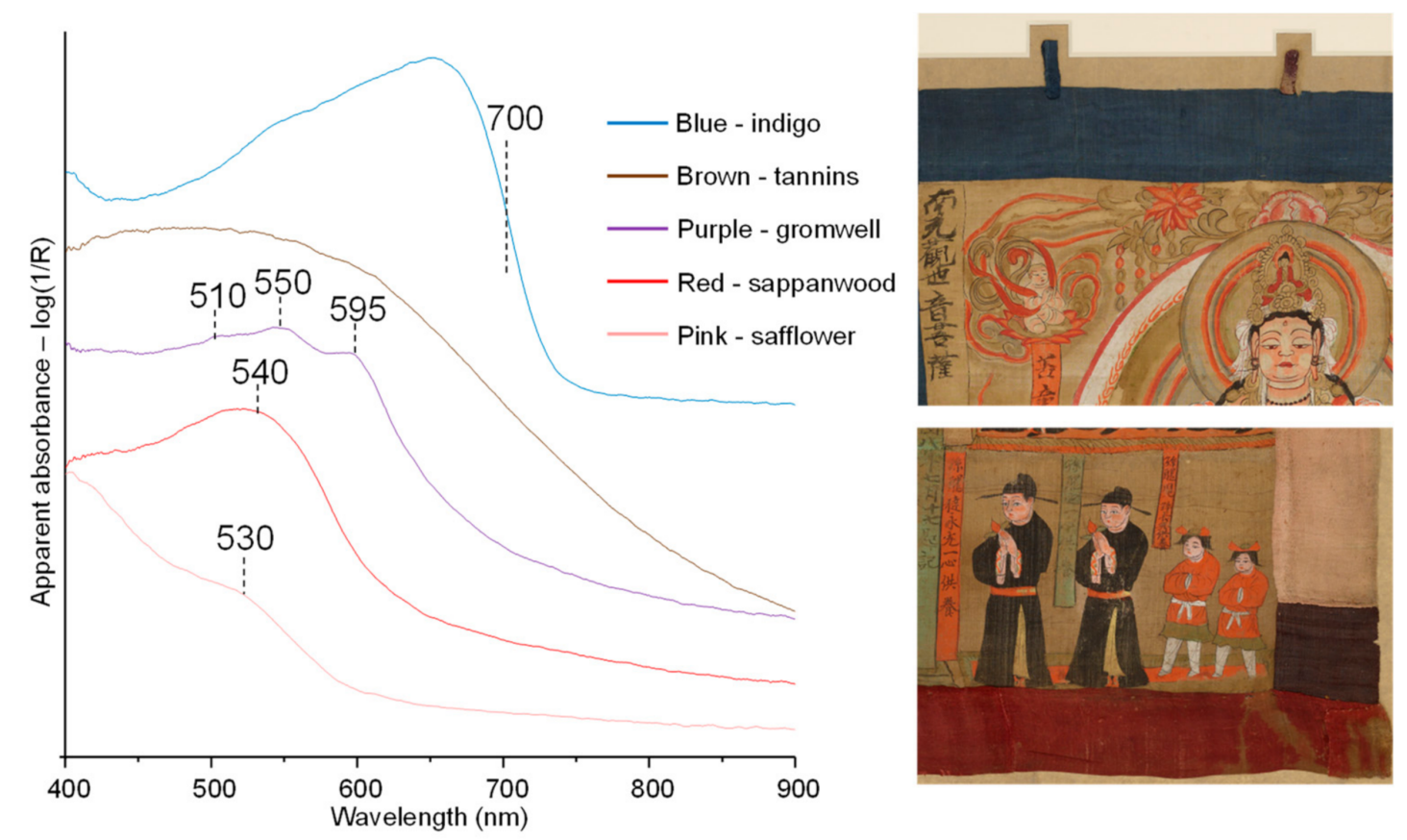

Figure 7. FORS spectra presented as apparent absorbance spectra obtained from the different parts of the multi-coloured border of DP54.

\subsection{Korean Painting}

The portrait of Ch'ae Che-Gong in its original Korean mounting is one of the finest expressions of Korean portraiture and one of the few surviving paintings of its kind. An invasive approach was therefore not advisable for this object. Therefore, FORS was used again to gain information on the dyes used in the various components of the mounting.

The aqua colour on the front of the silk mounting produced a relatively weak reflectance spectrum, showing the characteristic inflection point of indigo at ca. $700 \mathrm{~nm}[55,56,79]$. The spectrum is shown in apparent absorbance mode in Figure 8a for consistency with the other spectra reported. The back of the silk mounting is a darker shade of blue. FORS analysis produced a more intense signal compared to the light colour in the front, and the positioning of the inflection point still revealed the presence of indigo (Figure 8b). It is likely that the light and dark shades of blue were obtained by using unfermented and fermented indigo leaves, respectively [80]. Factors such as the number of dye baths and/or the concentration of indigo in the vat can also affect the final blue shade obtained [10,81]. The exact source of the indigo plant used cannot be identified, even with molecular analysis. Indian indigo (Indigofera tinctoria), woad (Isatis tinctoria), Persicaria tinctoria and Strobilanthes cusia are all reasonable options [22]. 
The spectra obtained from the red knotted tassels (yuso) were not particularly structured. However, a weak absorption maximum centred around $540 \mathrm{~nm}$ was visible (Figure $8 \mathrm{c}$ ). The positioning of the maximum and the lack of other spectral features suggest sappanwood as the most likely red dye in the tassels. However, the spectrum possibly shows the presence of a yellow component as well, as suggested by the strong absorption band centred at ca. $440 \mathrm{~nm}$ (Figure 8c). Yellow dyes cannot be easily differentiated by FORS [11,82], but the dark orange shade of the tassels is consistent with a possible mixture of red and yellow dyes.
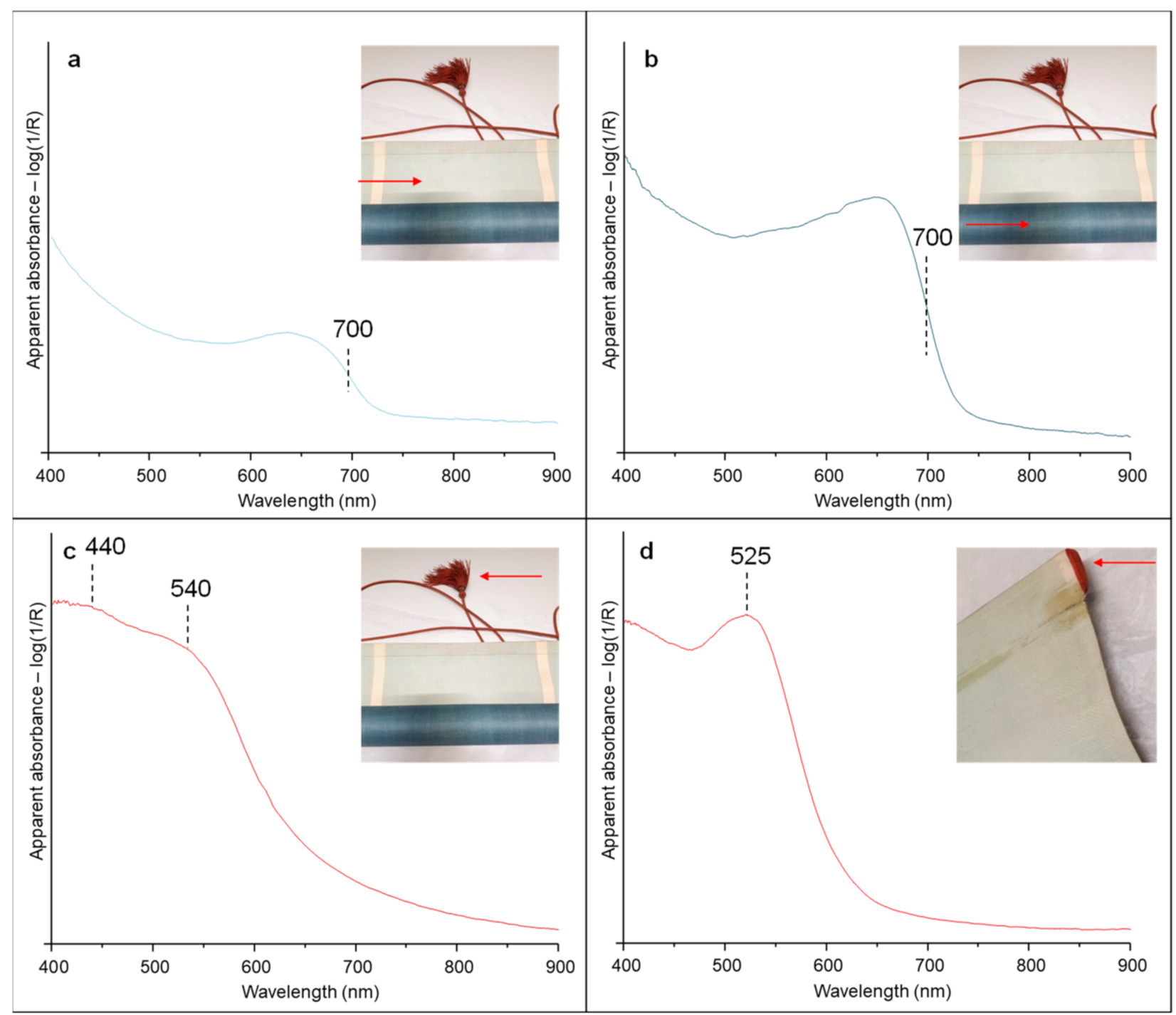

Figure 8. FORS spectra presented as apparent absorbance spectra obtained from the different parts of the mounting of K1: (a) aqua colour from the front; (b) dark blue from the back; (c) red from the tassels; (d) red from the faces of the hanging rod.

The faces of each side of the upper hanging rod were wrapped/covered with a small piece of red-dyed textile, which was also analysed. The spectrum obtained by FORS revealed the use of safflower, as can be observed by the strong absorption maximum at ca. $525-530 \mathrm{~nm}$ (Figure 8d).

\subsection{Thangkas}

The study of the thangkas under consideration occurred in the framework of a holistic conservation campaign, during which, in addition to stabilising the paintings by consolidating the unstable pigments, particular attention was given to the textile borders, which 
were initially separated from the paintings to allow for the fragile light-damaged silk to be treated. At this stage, access to the back of the textiles was possible, more accurately revealing the extent of light damage undergone by the dyes. This also represented an opportunity to take small samples from the various coloured threads and analyse them by HPLC-MS/MS.

The results of the dye analysis are summarised in Table 1.

Table 1. Summary of the results obtained by HPLC-MS/MS analysis of 9 samples taken from T1 and T2. The identified molecules and the corresponding plant sources are reported.

\begin{tabular}{|c|c|c|}
\hline \multicolumn{3}{|c|}{ T1 (Accession Number $1956,0714,0.40$ ) } \\
\hline Colour & Molecules & Dye plants \\
\hline Red & $\begin{array}{l}\text { 3-deoxysappanone B, sappanol, } \\
\text { byakangelicin, brasilein, sappanone B, } \\
\text { urolithin C, brasilin, protosappanin E }\end{array}$ & Sappanwood \\
\hline Pink & Carthamin & Safflower \\
\hline Green & $\begin{array}{l}\text { Rutin, kaempferol rutinoside, } \\
\text { isorhamnetin rutinoside, quercetin, } \\
\text { indigotin, indirubin }\end{array}$ & Pagoda tree and indigo \\
\hline Blue & Indigotin, indirubin & Indigo \\
\hline \multicolumn{3}{|c|}{ T2 (Accession Number $1956,0714,0.41$ ) } \\
\hline Colour & Molecules & Dye plants \\
\hline Dark orange & $\begin{array}{l}\text { 3-deoxysappanone B, sappanol, } \\
\text { byakangelicin, brasilein, sappanone B, } \\
\text { urolithin C, brasilin, protosappanin E, } \\
\text { bisdemethoxycurcumin, } \\
\text { demethoxycurcumin, curcumin }\end{array}$ & Sappanwood and turmeric \\
\hline Pink & Carthamin & Safflower \\
\hline Yellow & $\begin{array}{l}\text { Bisdemethoxycurcumin, } \\
\text { demethoxycurcumin, curcumin }\end{array}$ & Turmeric \\
\hline Dark yellow & $\begin{array}{l}\text { 3-deoxysappanone B, sappanol, } \\
\text { byakangelicin, brasilein, sappanone B, } \\
\text { urolithin C, brasilin, protosappanin E, } \\
\text { bisdemethoxycurcumin, } \\
\text { demethoxycurcumin, curcumin }\end{array}$ & Turmeric and sappanwood \\
\hline Blue & Indigotin, indirubin & Indigo \\
\hline
\end{tabular}

The results showed that all the dyes are natural, thus confuting initial doubts about the presence of synthetic dyes and supporting the hypothesis that the textile borders are likely to be contemporaneous with the paintings, or even older.

Red was obtained by using sappanwood. As the samples were taken from the back of the textiles, which had not been exposed to light, the preservation of the dyeing molecules from sappanwood was remarkable. Many molecular markers were detected, including urolithin C, which is commonly detected even upon degradation [50], but also brasilin, brasilein, sappanol, protosappanin $\mathrm{E}$ and others, which are detected only when the preservation state is very good (Figure 9c) [12]. Sappanwood was also found mixed with the yellow dye from turmeric (Curcuma longa) to obtain dark orange and dark yellow shades, by mixing different amounts of the two dyes (Figure 9c). Turmeric was also the source of yellow for the pure yellow colour. However, in the case of green, the yellow dye mixed with indigo was found to be extracted from the pagoda tree (Sophora japonica) flower buds (Figure $9 \mathrm{~b}$ ). This combination of dyes to obtain green was identified in another late 18thcentury thangka [83]. The use of different sources of yellow in the same textile has been observed before [12,13], and the preferential use of pagoda tree yellow, in combination with indigo, to obtain green shades is reported in various texts [24]. In fact, the yellow colour obtained from this plant already has a slightly greenish hue, which probably makes it more suitable for dyeing green than the vibrant yellow from turmeric [11]. The higher light sen- 
sitivity of turmeric compared to pagoda tree yellow [11] may have also been an important consideration for dyers, as fading of the yellow would severely compromise the intended shade of green. Pure blue areas were dyed with indigo and, as already highlighted, it is difficult to speculate further about the plant from which indigo was extracted. Indian indigo (Indigofera tinctoria), woad (Isatis tinctoria), Persicaria tinctoria and Strobilanthes cusia are among the most probable sources. The pink areas were dyed with safflower. Figure 9a shows that only carthamin was detected, which is an indication of the extremely good preservation of the pink colour on the back of the textiles. By contrast, on the front, a much lighter pink can be observed, as a result of the light sensitivity of safflower.

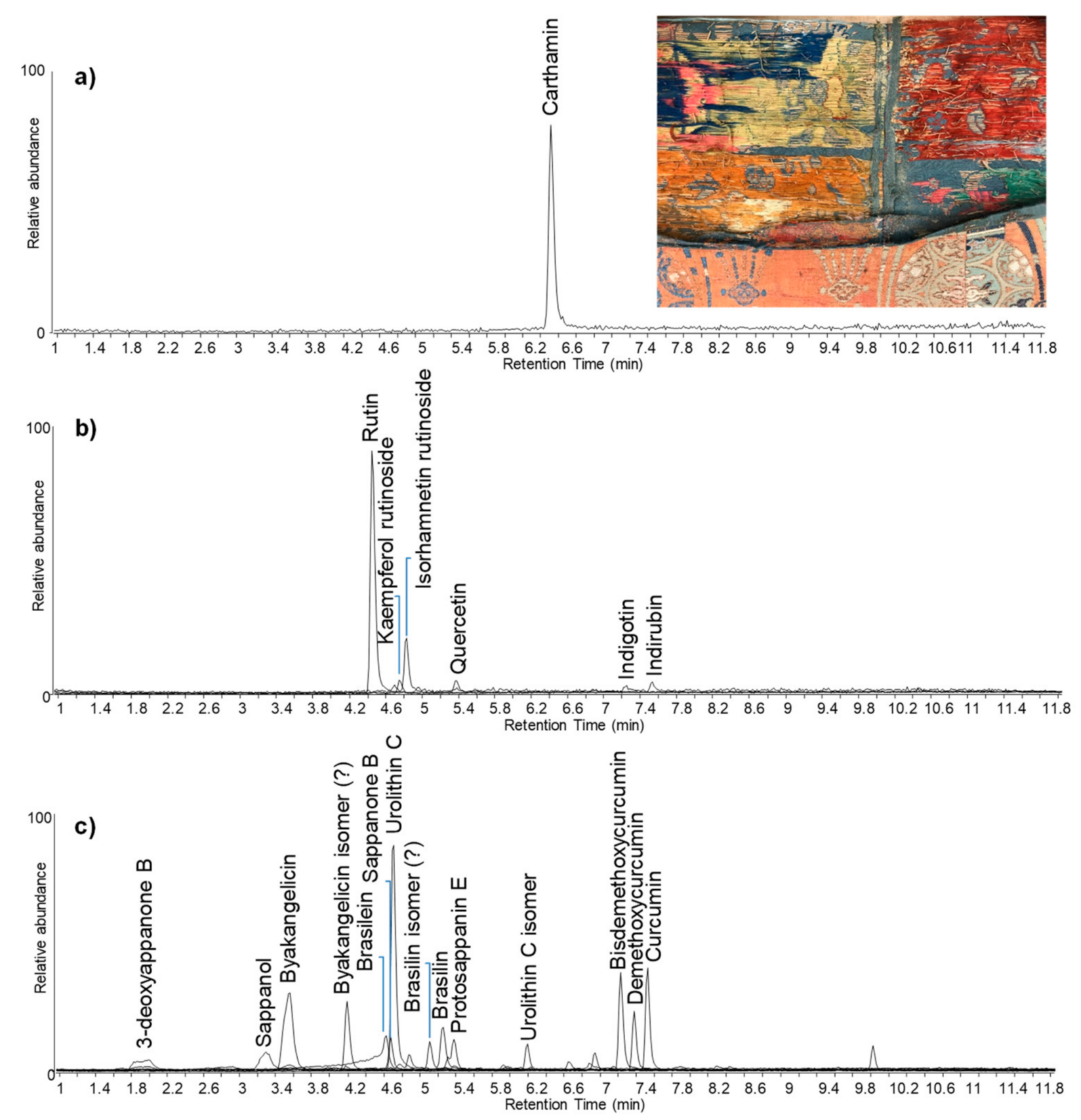

Figure 9. Extracted ion chromatograms of the main molecular components obtained by HPLC-MS/MS analysis (negative mode) of (a) pink sample from T1, (b) green sample from T1, and (c) red/orange sample from T2. An image of the back of the textile borders of $\mathrm{T} 1$ is also reported to show the vibrant non-faded colours. 


\section{Discussion}

The results obtained reflect the advantages and limitations of the analytical techniques adopted. The non-invasive analyses by FORS enabled several dyes, such as safflower, sappanwood, gromwell, tannins and indigo, to be identified without the need for sampling. Of particular interest is the non-invasive distinction between discoloured purple from gromwell and actual brown from tannins in the Dunhuang paintings. On the other hand, one limitation of the non-invasive approach is the possibility to miss the presence of other dyes potentially present as minor components. In the case of gromwell, for example, previous analyses on Dunhuang textiles have shown that the purple dye was rarely used alone, but rather in mixture with madder (Rubia spp.) and/or sappanwood (B. sappan) $[12,13]$. It would be interesting to see if this is the case for these textile borders as well. However, as already explained, sampling was not possible at this stage. DP23 also represents a rare example in which gromwell is used to dye a cellulosic fabric. As cellulosic fibres are generally more difficult to dye than proteinaceous ones, and gromwell is a difficult dye to use [43], this finding represents an interesting topic for further investigation. The limitation of FORS to identify most yellow dyes was also confirmed in this study. For example, in the knotted tassels of the Korean painting, a yellow dye is suspected to be mixed with sappanwood, but no additional information on its nature was obtainable by FORS.

By contrast, the molecular identification provided by HPLC-MS/MS, when sampling is possible, enables mixtures to be readily identified. In addition, the dyeing techniques for the mixed orange (sappanwood and turmeric) and green (indigo and pagoda tree) shades found in the textile borders of the thangkas are in agreement with traditional Chinese recipes adopted during the Ming and Qing dynasties [24], which supports the hypothesis that a Chinese robe of high quality may have been re-used in these mountings. The use of recycled textiles is common in thangka mounting [5]. In some cases, it can be simply due to the fact that only used textiles are available at the time of mounting. However, for very important thangkas used for specific ceremonies and occasions, garments associated with important monks would have been used, so that borders are imbued with and perpetuate that particular person's spiritual nature [5].

More generally, the analyses provided valuable contextual information about the materials used to dye the textile borders and mount elements. These all appeared to be local materials in line with traditional dyeing recipes of the respective geographical areas $[12,22,83,84]$. Additionally, the results confirm that some of the borders were originally brighter, more colourful and, in some cases, even had a different colour. However, it is worth mentioning that mordants are important components of obtaining a specific colour shade during dyeing [10]. In this investigation, mordant identification was not possible, but this information is generally helpful to obtain precise colour reconstructions.

Nevertheless, for the Dunhuang paintings, the reconstruction of the original colours of the textile borders showed that deep purple, bright red, pink, blue and brown were chosen to emphasise the main colours and the focal points of the paintings, by echoing them, complementing them, or even somehow contrasting them. However, this is not the case for all Dunhuang paintings, as lighter colours also feature in some textile borders. A broader contextualisation of the role of the textile borders and their colours in a higher number of Dunhuang paintings in the BM collection is currently in progress [58].

The concept of complementing colours between the textile borders and the painting itself finds its maximum expression in the Korean painting of Ch'ae Che-Gong. The aqua colour balances the pink of the robe perfectly and shows brilliant mastery of the art of shading indigo, which is a complex operation in itself, with the final result of further enhancing the beauty of the fine silk. Such works were normally kept in the estate of the sitter's family and used for ceremonies in ancestor worship. Therefore, the mount played an active role in defining and shaping social status [6]. The tassels, the delicate pastel colours, the safflower detail of the hanging rod are all elements that are aligned with the aim of attaining elegance and perfection. With regards to the safflower detail, attaining such a vibrant red colour by using safflower is remarkable, as lighter shades of pink and oranges 
(as seen in the Dunhuang paintings) are generally obtained from safflower petals due to the difficulty of completely separating the red and yellow dyes naturally present together in the flower. In fact, there are different methods to extract the red colourant (carthamin) from the safflower petals [10]. Regardless of the exact extraction and application methods, which cannot be ascertained on the sole basis of these results, achieving such a relatively pure red from safflower is an indication of a very time-consuming and careful process, which reflects the high quality of the whole artwork.

For the thangkas, the possibility to access the back of the brocades was an invaluable opportunity to see the original colours, which are heavily faded on the front. The abundance of decorative elements in the brocades enriches the ensemble of the painting and reveals an opposite trend compared to the Korean painting. The Korean mounting exploits simplicity to embellish the artwork, whereas in the thangkas the opulence of the borders exalts the painting. In addition, the borders on a thangka are intended as a portal to the significance of the spiritual emanations of the image represented. This is partially obtained by using specific colours carrying symbolic value. Regardless of the level of decoration, in Central Tibetan-style mounts the inner borders next to the painting are usually of the same set of colours and are referred to as "red and yellow rainbow" (ia dmar ser) [4,7]. The distinctive cloth patch (thang sgo or "door") on the lower part of the mount shows water symbols, whereas the lower part of the mount symbolises the earth, as opposed to the upper part of the mount that symbolises the sky [4,7]. The results from this investigation show how bright and powerful these symbolic colours were originally intended to be as opposed to how they appear now. In particular, the red and yellow inner textile borders show variable levels of fading and discolouration, which are consistent with the dye sources (sappanwood and turmeric) identified in this study [11]. Figure 10 reports images of the front and back of the borders, showing the original colours intended for the "red and yellow rainbow". Interesting parallels can also be drawn from the images of the thangkas in the Tucci collection in the Museo Nazionale d'Arte Orientale (Rome, Italy), where a wide range of yellow, orange and red colours are visible in the inner textile borders, thus showing that the results obtained from a few samples can potentially in-form on a higher number of objects [5].
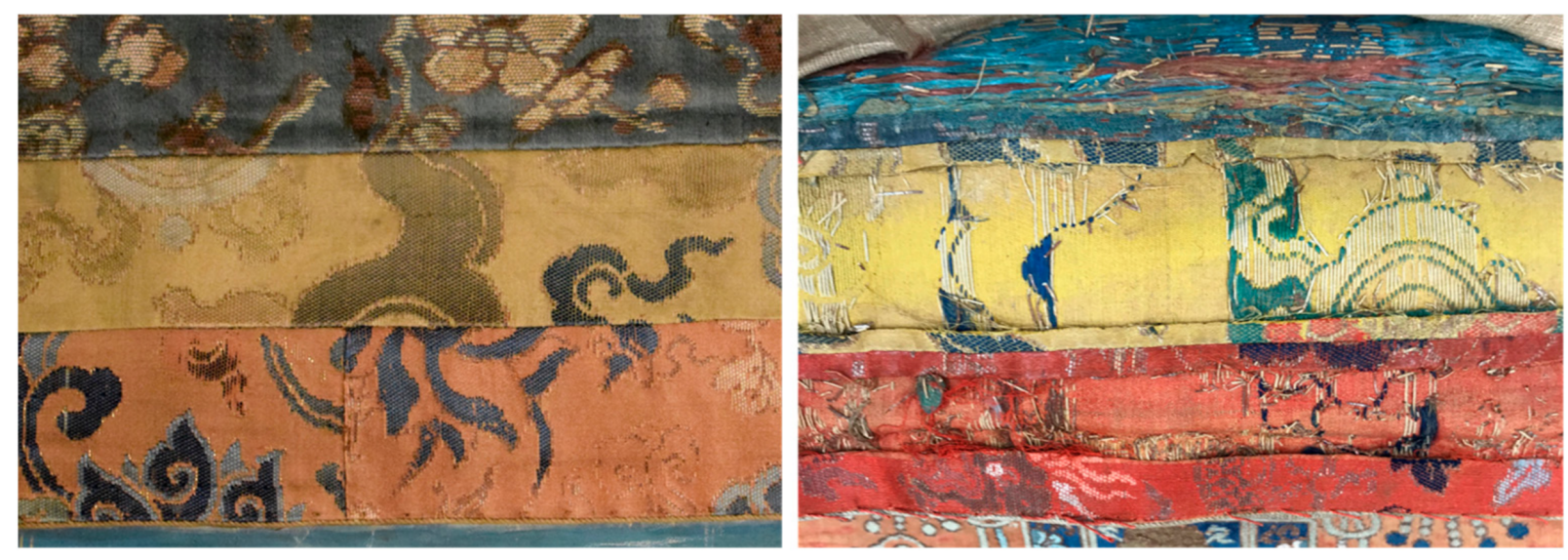

Figure 10. Images of the front (left) and back (right) of the inner textile borders of T1, showing the extent of colour fading.

Pieces of the same textiles appear to be used within the borders of not only T1 and T2 but also three additional thangkas in the BM collection (1956,0714,0.42-44), which are supposedly a set that may have once hung in a monastic assembly hall in Tibet [68]. The paintings are executed in quite different styles, which suggests that they became a set once the textile mountings were added, but they were probably not initially intended as a set. Therefore, the results of this investigation can be extended to more objects in the collection. 
Finally, the identification of the dye sources is also interesting from the conservation perspective. The good preservation of light-sensitive dyes, such as safflower, sappanwood, turmeric and gromwell in some of the textiles makes it even more important to limit display and light exposure in the future. By contrast, in the cases when these dyes already show an advanced level of fading or discolouration, research is ongoing to understand whether the dyes reach a threshold of light stability after which the risk of light exposure is minimised so that they can be displayed in a more relaxed way. However, these choices cannot be made without considering the light sensitivity of the pigments in the paintings as well [66].

\section{Conclusions}

In this study, several dye sources were identified in the textile borders and some mounting elements of six Chinese paintings from the Library Cave, Mogao Grottoes, Dunhuang (late 9th-10th century CE), one rare Korean portrait painting dated $1789 \mathrm{CE}$, and two Tibetan thangkas (18th century).

For the Dunhuang and Korean paintings, non-invasive analysis by FORS enabled indigo, tannins, safflower, sappanwood and gromwell to be identified as the main dyes used to obtain blue, brown, pink, red and purple shades, respectively. Additionally, a very good preservation state of the colours in the Korean painting was highlighted, whereas different levels of fading and discolouration were present in the Dunhuang paintings. It was possible to non-invasively clarify doubts around some borders in the Dunhuang paintings that appear brown today but would have originally looked purple, thus providing valuable information about the original artistic intention and enhancing the understanding of the artworks.

For the thangkas, invasive analysis by HPLC-MS/MS was possible, as the textile borders were accessible from the back. The analyses produced accurate results, including the identification of yellow dyes (pagoda tree and turmeric), in addition to sappanwood, safflower and indigo used to obtain the various colours. The information on the light sensitivity of the dyes was fundamental to reconstruct the original appearance of the silk brocades, which underwent substantial fading.

Although textile borders in Asian paintings are often considered a peripheral topic, this study highlights the useful complementary information that can be obtained by analysing these mounting components, which are an integral part of the artworks and deserve attention, in order to correctly preserve, display and interpret such precious heritage. Finally, the work highlights how ethically driven compromises commonly made in museum settings may limit the range of suitable analytical approaches. However, significant information can still be yielded whilst minimising damage to the objects.

Author Contributions: Conceptualisation, D.T., J.D., T.H., A.D., M.K.-M., M.P., Y.-P.L. and I.R.; methodology, D.T. and J.D.; formal analysis, D.T. and J.D.; investigation, D.T. and J.D.; resources, T.H., M.K.-M., Y.-P.L. and I.R.; data curation, D.T. and J.D.; writing—original draft preparation, D.T.; writing—-review and editing, D.T., J.D., T.H., A.D., M.K.-M., M.P., Y.-P.L. and I.R.; visualisation, D.T. All authors have read and agreed to the published version of the manuscript.

Funding: This research received no external funding.

Data Availability Statement: The data presented in this study are available on request from the corresponding author.

Acknowledgments: The authors would like to thank Christian Luczanits for examining the series of Mahasiddha thangkas and transliterating the accompanying inscriptions, which identify the figures pictured. The authors would like to express their gratitude to Boyoung Lee for her insights into traditional Korean dyes.

Conflicts of Interest: The authors declare no conflict of interest. 


\section{References}

1. Van Gulik, R. Chinese Pictorial Art as Viewed by the Connoisseur: Notes on the Means and Methods of Traditonal Chinese Connisseurship of Pictorial Art, Based upon a Study of the Art of Mounting Scrolls in China and Japan; Instituto Italiano per il Medio ed Estremo Oriente: Rome, Italy, 1958.

2. Kim-Marandet, M. The Mounting of Korean Painting during the Joseon Dynasty (1392); Sorbonne University: Paris, France, 2018.

3. Zhang, H. Masterpieces of Chinese Painting, 700-1900; The V \& A: London, UK, 2013; pp. 11-25.

4. Huntington, J.C. The iconography and structure of the mountings of Tibetan paintings. Stud. Conserv. 1970, 15, 190-205. [CrossRef]

5. Klimburg-Salter, D. Discovering Tibet: The Tucci Expeditions and Tibetan Paintings; Klimburg-Salter, D., Ed.; Skira: Lausanne, Swizerland, 2016; p. 286.

6. Kim, M. Broken history: Redefining eighteenth-century Korean portrait painting mounts. Stud. Conserv. 2014, 59, S58-S61. [CrossRef]

7. Elgar, J. Tibetan thang kas: An overview. Pap. Conserv. 2006, 30, 99-114. [CrossRef]

8. Painting Formats in East Asian Art. Heilbrunn Timeline Art History. Available online: http://www.metmuseum.org/toah/hd/ pfor/hd_pfor.htm (accessed on 15 September 2021).

9. Shaftel, A. Conservation Treatment of Tibetan Thangkas. J. Am. Inst. Conserv. 1991, 30, 3-11. [CrossRef]

10. Cardon, D. Le Monde des Teintures Naturelles; Belin: Paris, France, 2014.

11. Tamburini, D.; Dyer, J. Fibre optic reflectance spectroscopy and multispectral imaging for the non-invasive investigation of Asian colourants in Chinese textiles from Dunhuang (7th-10th century AD). Dyes Pigment. 2019, 162, 494-511. [CrossRef]

12. Tamburini, D. Investigating Asian colourants in Chinese textiles from Dunhuang (7th-10th century AD) by high performance liquid chromatography tandem mass spectrometry-Towards the creation of a mass spectra database. Dyes Pigment. 2019, 163, 454-474. [CrossRef]

13. Tamburini, D.; Cartwright, C.R.; Pullan, M.; Vickers, H. An investigation of the dye palette in Chinese silk embroidery from Dunhuang (Tang dynasty). Archaeol. Anthropol. Sci. 2019, 11, 1221-1239. [CrossRef]

14. Grzywacz, C.M.; Wouters, J.; Bomin, S.; Yuquan, F. Conservation of Ancient Sites on the Silk Road-Asian Organic Colourants: A collaborative research project. In Proceedings of the Second International Conference on the Conservation of Grotto Sites, Mogao Grottoes, Dunhuang, China, 28 June-3 July 2004.

15. Han, J.; Wanrooij, J.; van Bommel, M.; Quye, A. Characterisation of chemical components for identifying historical Chinese textile dyes by ultra high performance liquid chromatography—Photodiode array-Electrospray ionisation mass spectrometer. J. Chromatogr. A 2017, 1479, 87-96. [CrossRef]

16. De Luca, E.; Poldi, G.; Redaelli, M.; Zaffino, C.; Bruni, S. Multi-technique investigation of historical Chinese dyestuffs used in Ningxia carpets. Archaeol. Anthropol. Sci. 2017, 9, 1789-1798. [CrossRef]

17. Laursen, R.; Mouri, C.; Feng, Z.; Bo, L.; Jian, L. Section III—Dyes in Ancient Chinese and Japanese Textiles. In Color in Ancient and Medieval East Asia; Dusenbury, M.M., Ed.; Spencer Museum of Art, University of Kansas: Lawrence, KS, USA, 2015 ; pp. 81-113.

18. Zhang, X.; Good, I.; Laursen, R. Characterization of dyestuffs in ancient textiles from Xinjiang. J. Archaeol. Sci. 2008, 35, 1095-1103. [CrossRef]

19. Zhang, X.; Corrigan, K.; MacLaren, B.; Leveque, M.; Laursen, R. Characterization of Yellow Dyes in Nineteenth-Century Chinese Textiles. Stud. Conserv. 2007, 52, 211-220. [CrossRef]

20. Karpova, E.; Vasiliev, V.; Mamatyuk, V.; Polosmak, N.; Kundo, L. Xiongnu burial complex: A study of ancient textiles from the 22nd Noin-Ula barrow (Mongolia, first century AD). J. Archaeol. Sci. 2016, 70, 15-22. [CrossRef]

21. Jolly, A.; Vanden Berghe, I.; Wouters, J. Europe or China? Dyestuff analyses as a tool for attributions. In The Diversity of Dyes in History and Archaeology; Kirby, J., Ed.; Archetype Publications: London, UK, 2017; pp. 6-17.

22. Liu, J.; Li, W.; Kang, X.; Zhao, F.; He, M.; She, Y.; Zhou, Y. Profiling by HPLC-DAD-MSD reveals a 2500-year history of the use of natural dyes in Northwest China. Dyes Pigment. 2021, 187, 109143. [CrossRef]

23. Tamburini, D.; Breitung, E.; Mori, C.; Kotajima, T.; Clarke, M.L.; McCarthy, B. Exploring the transition from natural to synthetic dyes in the production of 19th-century Central Asian ikat textiles. Herit. Sci. 2020, 8, 114. [CrossRef]

24. Han, J.; Quye, A. Dyes and Dyeing in the Ming and Qing Dynasties in China: Preliminary Evidence Based on Primary Sources of Documented Recipes. Text. Hist. 2018, 49, 44-70. [CrossRef]

25. Chen, V.J.; Smith, G.D.; Holden, A.; Paydar, N.; Kiefer, K. Chemical analysis of dyes on an Uzbek ceremonial coat: Objective evidence for artifact dating and the chemistry of early synthetic dyes. Dyes Pigment. 2016, 131, 320-332. [CrossRef]

26. Liu, J.; Zhou, Y.; Zhao, F.; Peng, Z.; Wang, S. Identification of early synthetic dyes in historical Chinese textiles of the late nineteenth century by high-performance liquid chromatography coupled with diode array detection and mass spectrometry. Coloration Technol. 2016, 132, 177-185. [CrossRef]

27. Liu, J.; Mouri, C.; Laursen, R.; Zhao, F.; Zhou, Y.; Li, W. Characterization of dyes in ancient textiles from Yingpan, Xinjiang. J. Archaeol. Sci. 2013, 40, 4444-4449. [CrossRef]

28. Lee, J.; Kang, M.; Lee, K.-B.; Lee, Y. Characterization of Natural Dyes and Traditional Korean Silk Fabric by Surface Analytical Techniques. Materials 2013, 6, 2007-2025. [CrossRef] 
29. Nakamura, R.; Tanaka, Y.; Ogata, A.; Naruse, M. Dye Analysis of Shosoin Textiles Using Excitation-Emission Matrix Fluorescence and Ultraviolet-Visible Reflectance Spectroscopic Techniques. Anal. Chem. 2009, 81, 5691-5698. [CrossRef]

30. Sasaki, Y.; Sasaki, K. Dye analysis of a 17th-century historic Japanese textile: A non-destructive approach. In The Diversity of Dyes in History and Archaeology; Kirby, J., Ed.; Archetype Publications: London, UK, 2017; pp. 265-277.

31. Kato, K.; Doherty, B.; Degano, I.; Sabatini, F.; Miliani, C.; Romani, A.; Ito, K.; Brunetti, B.G. An SERS analytical protocol for characterizing native Japanese plant extracts. J. Raman Spectrosc. 2020, 51, 892-902. [CrossRef]

32. Lux, C.; Lubio, A.; Ruediger, A.; Robert, S.; Muehlethaler, C. Optimizing the analysis of dyes by Surface-Enhanced Raman Spectroscopy (SERS) using a conventional-microwave silver nanoparticles synthesis. Forensic Chem. 2019, 16, 100186. [CrossRef]

33. Cesaratto, A.; Leona, M.; Pozzi, F. Recent Advances on the Analysis of Polychrome Works of Art: SERS of Synthetic Colorants and Their Mixtures With Natural Dyes. Front. Chem. 2019, 7, 105. [CrossRef]

34. Mounier, A.; Le Bourdon, G.; Aupetit, C.; Lazare, S.; Biron, C.; Pérez-Arantegui, J.; Almazán, D.; Aramendia, J.; Prieto-Taboada, N.; Fdez-Ortiz de Vallejuelo, S.; et al. Red and blue colours on 18th-19th century Japanese woodblock prints: In situ analyses by spectrofluorimetry and complementary non-invasive spectroscopic methods. Microchem. J. 2018, 140, 129-141. [CrossRef]

35. Derrick, M.; Newman, R.; Wright, J. Characterization of Yellow and Red Natural Organic Colorants on Japanese Woodblock Prints by EEM Fluorescence Spectroscopy. J. Am. Inst. Conserv. 2017, 56, 171-193. [CrossRef]

36. Dyer, J.; Tamburini, D.; Sotiropoulou, S. The identification of lac as a pigment in ancient Greek polychromy-The case of a Hellenistic oinochoe from Canosa di Puglia. Dyes Pigment. 2018, 149, 122-132. [CrossRef]

37. Degano, I.; Ribechini, E.; Modugno, F.; Colombini, M.P. Analytical Methods for the Characterization of Organic Dyes in Artworks and in Historical Textiles. Appl. Spectrosc. Rev. 2009, 44, 363-410. [CrossRef]

38. Mouri, C.; Laursen, R. Identification of anthraquinone markers for distinguishing Rubia species in madder-dyed textiles by HPLC. Microchim. Acta 2012, 179, 105-113. [CrossRef]

39. Mouri, C.; Mozaffarian, V.; Zhang, X.; Laursen, R. Characterization of flavonols in plants used for textile dyeing and the significance of flavonol conjugates. Dyes Pigment. 2014, 100, 135-141. [CrossRef]

40. Serrano, A.; van den Doel, A.; van Bommel, M.; Hallett, J.; Joosten, I.; van den Berg, K.J. Investigation of crimson-dyed fibres for a new approach on the characterization of cochineal and kermes dyes in historical textiles. Anal. Chim. Acta 2015, 897, 116-127. [CrossRef]

41. Santos, R.; Hallett, J.; Oliveira, M.C.; Sousa, M.M.; Sarraguça, J.; Simmonds, M.S.J.; Nesbitt, M. HPLC-DAD-MS analysis of colorant and resinous components of lac-dye: A comparison between Kerria and Paratachardina genera. Dyes Pigment. 2015, 118, 129-136. [CrossRef]

42. Lech, K.; Jarosz, M. Identification of Polish cochineal (Porphyrophora polonica L.) in historical textiles by high-performance liquid chromatography coupled with spectrophotometric and tandem mass spectrometric detection. Anal. Bioanal. Chem. 2016, 408, 3349-3358. [CrossRef] [PubMed]

43. Wouters, J.; Grzywacz, C.M.; Claro, A. A Comparative Investigation of Hydrolysis Methods to Analyze Natural Organic Dyes by HPLC-PDA-Nine Methods, Twelve Biological Sources, Ten Dye Classes, Dyed Yarns, Pigments and Paints. Stud. Conserv. 2011, 56, 231-249. [CrossRef]

44. Vanden Berghe, I.; Gleba, M.; Mannering, U. Towards the identification of dyestuffs in Early Iron Age Scandinavian peat bog textiles. J. Archaeol. Sci. 2009, 36, 1910-1921. [CrossRef]

45. Karapanagiotis, I.; Theologou, J.; Lakka, A.; Ozoline, A.; Panayiotou, C. Investigation of the colouring materials of Fustat carpet fragments. Archaeometry 2011, 53, 587-599. [CrossRef]

46. Sabatini, F.; Degano, I.; Colombini, M.P. Development of a method based on high-performance liquid chromatography coupled with diode array, fluorescence, and mass spectrometric detectors for the analysis of eosin at trace levels. Sep. Sci. Plus 2020, 3 , 207-215. [CrossRef]

47. Mouri, C.; Laursen, R. Identification and partial characterization of C-glycosylflavone markers in Asian plant dyes using liquid chromatography-tandem mass spectrometry. J. Chromatogr. A 2011, 1218, 7325-7330. [CrossRef]

48. Sasaki, Y.; Sasaki, K. Analysis of protoberberines in historical textiles: Determining the provenance of East Asian textiles by analysis of phellodendron. E-Preserv. Sci. 2013, 10, 83-89.

49. Wouters, J.; Grzywacz, C.M.; Claro, A. Markers for Identification of Faded Safflower (Carthamus tinctorius L.) Colorants by HPLC-PDA-MS-Ancient Fibres, Pigments, Paints and Cosmetics Derived from Antique Recipes. Stud. Conserv. 2010, 55, 186-203. [CrossRef]

50. Peggie, D.A.; Kirby, J.; Poulin, J.; Genuit, W.; Romanuka, J.; Wills, D.F.; De Simone, A.; Hulme, A.N. Historical mystery solved: A multi-analytical approach to the identification of a key marker for the historical use of brazilwood (Caesalpinia spp.) in paintings and textiles. Anal. Methods 2018, 10, 617-623. [CrossRef]

51. Degano, I.; Tognotti, P.; Kunzelman, D.; Modugno, F. HPLC-DAD and HPLC-ESI-Q-ToF characterisation of early 20th century lake and organic pigments from Lefranc archives. Herit. Sci. 2017, 5, 7. [CrossRef]

52. Troalen, L.G.; Phillips, A.S.; Peggie, D.A.; Barranac, P.E.; Hulme, A.N. Historical textile dyeing with Genista tinctoria L.: A comprehensive study by UPLC-MS/MS analysis. Anal. Methods 2014, 6, 8915-8923. [CrossRef] 
53. Degano, I.; Mattonai, M.; Sabatini, F.; Colombini, M.P. A Mass Spectrometric Study on Tannin Degradation within Dyed Woolen Yarns. Molecules 2019, 24, 2318. [CrossRef]

54. Nabais, P.; Oliveira, J.; Pina, F.; Teixeira, N.; de Freitas, V.; Brás, N.F.; Clemente, A.; Rangel, M.; Silva, A.M.S.; Melo, M.J. A 1000-year-old mystery solved: Unlocking the molecular structure for the medieval blue from Chrozophora tinctoria, also known as folium. Sci. Adv. 2020, 6, eaaz7772. [CrossRef]

55. Vermeulen, M.; Tamburini, D.; Müller, E.M.K.; Centeno, S.A.; Basso, E.; Leona, M. Integrating liquid chromatography mass spectrometry into an analytical protocol for the identification of organic colorants in Japanese woodblock prints. Sci. Rep. 2020, 10, 20921. [CrossRef]

56. Dyer, J.; Tamburini, D.; O'Connell, E.R.; Harrison, A. A multispectral imaging approach integrated into the study of Late Antique textiles from Egypt. PLoS ONE 2018, 13, e0204699. [CrossRef]

57. Stein, A. Ruins of Desert Cathay: Personal Narrative of Explorations in Central Asia and Westernmost China; Macmillan \& Co., Ltd: London, UK, 1912; Volume I \& II.

58. Luk, Y.-P. Textile borders on paintings from Cave 17, Mogao Grottoes, Dunhuang. In Proceedings of the International Association for the Study of Silk Roads Textiles, Kislovodsk, Russia, 29-September-1 October 2019.

59. Available online: https://www.britishmuseum.org/collection/object/A_1919-0101-0-16 (accessed on 15 September 2021).

60. Available online: https://www.britishmuseum.org/collection/object/A_1919-0101-0-23 (accessed on 15 September 2021).

61. Available online: https://www.britishmuseum.org/collection/object/A_1919-0101-0-30 (accessed on 15 September 2021).

62. Available online: https://www.britishmuseum.org/collection/object/A_1919-0101-0-31 (accessed on 15 September 2021).

63. Available online: https://www.britishmuseum.org/collection/object/A_1919-0101-0-54 (accessed on 15 September 2021).

64. Available online: https://www.britishmuseum.org/collection/object/A_1919-0101-0-63 (accessed on 15 September 2021).

65. Available online: https://www.britishmuseum.org/collection/object/A_1996-0329-0-1 (accessed on 15 September 2021).

66. Dyer, J.; Derham, A.; O’Flynn, D.; Tamburini, D.; Heady, T.; Ramos, I. Studying Saraha: A multi-analytical protocol applied to the technical investigation of an 18 th century Tibetan thangka. In preparation for publication.

67. Shaftel, A. Notes on the Technique of Tibetan Thangkas. J. Am. Inst. Conserv. 1986, 25, 97-103. [CrossRef]

68. Ramos, I. Tantra: Enlightenment to Revolution; The British Museum, Thames \& Hudson: London, UK, $2020 ;$ p. 288.

69. Tamburini, D.; Cartwright, C.R.; Melchiorre Di Crescenzo, M.; Rayner, G. Scientific characterisation of the dyes, pigments, fibres and wood used in the production of barkcloth from Pacific islands. Archaeol. Anthropol. Sci. 2019, 11, 3121-3141. [CrossRef]

70. Tamburini, D.; Dyer, J.; Davit, P.; Aceto, M.; Turina, V.; Borla, M.; Vandenbeusch, M.; Gulmini, M. Compositional and MicroMorphological Characterisation of Red Colourants in Archaeological Textiles from Pharaonic Egypt. Molecules 2019, $24,3761$. [CrossRef]

71. Tamburini, D.; Dyer, J.; Vandenbeusch, M.; Borla, M.; Angelici, D.; Aceto, M.; Oliva, C.; Facchetti, F.; Aicardi, S.; Davit, P.; et al. A multi-scalar investigation of the colouring materials used in textile wrappings of Egyptian votive animal mummies. Herit. Sci. 2021, 9, 106. [CrossRef]

72. Tamburini, D.; Martin de Fonjaudran, C.; Verri, G.; Accorsi, G.; Acocella, A.; Zerbetto, F.; Rava, A.; Whittaker, S.; Saunders, D.; Cather, S. New insights into the composition of Indian yellow and its use in a Rajasthani wall painting. Microchem. J. 2018, 137, 238-249. [CrossRef]

73. Pereira-Pardo, L.; Tamburini, D.; Dyer, J. Shedding light on the colours of medieval alabaster sculptures: Scientific analysis and digital reconstruction of their original polychromy. Color Res. Appl. 2019, 44, 221-233. [CrossRef]

74. Berbers, S.V.J.; Tamburini, D.; van Bommel, M.R.; Dyer, J. Historical formulations of lake pigments and dyes derived from lac: A study of compositional variability. Dyes Pigment. 2019, 170, 107579. [CrossRef]

75. Stein, A. Serindia; Clarendon Press: Oxford, UK, 1921.

76. Aceto, M.; Calà, E. Analytical evidences of the use of iron-gall ink as a pigment on miniature paintings. Spectrochim. Acta Part A Mol. Biomol. Spectrosc. 2017, 187, 1-8. [CrossRef]

77. Aceto, M.; Agostino, A.; Fenoglio, G.; Idone, A.; Gulmini, M.; Picollo, M.; Ricciardi, P.; Delaney, J.K. Characterisation of colourants on illuminated manuscripts by portable fibre optic UV-visible-NIR reflectance spectrophotometry. Anal. Methods 2014, 6, 1488-1500. [CrossRef]

78. Costantini, R.; Vanden Berghe, I.; Izzo, F.C. New insights into the fading problems of safflower red dyed textiles through a HPLC-PDA and colorimetric study. J. Cult. Herit. 2019, 38, 37-45. [CrossRef]

79. Vermeulen, M.; Burgio, L.; Vandeperre, N.; Driscoll, E.; Viljoen, M.; Woo, J.; Leona, M. Beyond the connoisseurship approach: Creating a chronology in Hokusai prints using non-invasive techniques and multivariate data analysis. Herit. Sci. 2020 , 8, 62. [CrossRef]

80. Ju, J.-A.; Ryu, H.-S. Dyeing on cellulose fibres by the solution extracted from natural fresh leaves of indigo plant. J. Korean Soc. Dyers Finish. 2004, 16, 19-27.

81. Balfour Paul, J. Indigo and Blue: A Marriage Made in Heaven. Text. Mus. J. 2020, 47, 160-185. [CrossRef]

82. de Ferri, L.; Tripodi, R.; Martignon, A.; Ferrari, E.S.; Lagrutta-Diaz, A.C.; Vallotto, D.; Pojana, G. Non-invasive study of natural dyes on historical textiles from the collection of Michelangelo Guggenheim. Spectrochim. Acta Part A Mol. Biomol. Spectrosc. 2018, 204, 548-567. [CrossRef] 
83. Mass, J.; Huang, J.-F.; Fiske, B.; Shaftel, A.; Zhang, X.; Laursen, R.; Shimoda, C.; Matsen, C.; Bisulca, C. Tangka Production in the 18th-21st Centuries: Documenting the Introduction of Non-traditional Materials into Himalayan Painting Practice. In Proceedings of the Forum on the Conservation of Thangkas, Special Session of the ICOM-CC 15th Triennial Conference, New Delhi, India, 26 September 2008; pp. 108-117.

84. Kim, S.-Y. Kinds and Types of Dyes Used in the Joseon Dynasty. J. Korean Soc. Cloth. Text. 2014, 38, 201-215. [CrossRef] 